\title{
Hautkrankheiten.
}

\section{Allgemeines, Anatomie, Physiologie, allgem. und exper. Pathologie, path. Anatomie.}

von Zumbusch, Leo. Die Beziehungen der Hautkrankheiten zu Krankheiten anderer Organe. Aus Jesioneks: Praktische Ergebnisse auf dem Gebiete der Haut- und Geschlechtskrankheiten. Wiesbaden. Verlag von J. F. Bergmann. 1910.

Das vorliegende Kapitel hat zum Teil, besonders was die Beziehungen der Hautkrankheiten zu den Krankheiten des Stoffwechsels betrifft, in den letzten Jahren mehrfach eine sorgfältige kritische Bearbeitung gefunden, ich erwäbne nur die Arbeiten von Jadassohn und Bloch, so daß es außerordentlich schwer ist, in einer noch weiteren Umgrenzung, wie die des vorliegenden Themas ist, neue Gesichtspunkte hineinzubringen. Auch schon die geordnete Zusammenstellung der hierher gehörigen Tatsachen stellt eine außerordentliche Leistung dar und die ist von $\mathrm{Zum}$ bus $\mathrm{ch}$ durchaus geglückt. Der Stoff ist übersichtlich angeordnet und so ist es dem Leser leicht gemacht, ausgehend von den einzelnen Krankheitsgruppen ihre Einwirkungen auf das Hautorgan zu studieren.

Fritz Juliusberg (Posen).

Merk, Ludwig. Die Grundformender Hautkrankheiten vom Standpunkte des Unterrichtes. Unnas Dermatologische Studien (Unna-Festschrift, Bd. I). Bd. XX. p. 411.

Merk gebraucht bei seinen Vorlesungen folgendes Schema: 1. Makula - der Fleck, bzw. die Eleckungen. 2. Papula - das Knötchen. 3. Nodus - der Knoten. 4. Phyma - der Knollen. 5. Urtika - die Quaddel 6. Vesikula - das Bläschen und Bulla - die Blase. 7. Cysta die Zyste. 8. Eiter beherbergende Grundformen: Pustula - die Pustel; Impetigines; Ekthyma; Akne bzw. Follikulitis; der Abszeß. 9. Exkoriation - die Abschürfung. 10. Rhagas - die Schrunde. 11. Grundformen des Hautzerfalles: Hautnekrose und Hautgeschwür. 12. Squama - die Schuppe und andere Formen der Hornverbildung: Hornplatten - Laminae corneae; Hornwucherungen - Excrescentia cornea; schwielige 
Verdickung - Callositas. 13. Crusta - die Kruste. 14. Cicatrix - die Narbe. Weiter teilt er die Grundformen in statische and synzyklische.

Fritz Juliusberg (Posen).

Fürst, Moritz. Die Beziehungen des Schularztes zurProphylaxis der Hautkrankheiten. Unnas Dermatologische Studien (Unna, Festschrift, Bd. II). Bd XXI. p. 197.

Lesenswerte Ausführungen, nicht zum Roferat geeignet.

Unna. Die Sauerstofforte des tierischen Gewebes. Biolog. Abteilung des Ärztl. Vereines. Hamburg. 27. Febr. 1911.

Während die alten histologischen Färbungsmethoden nur Oxybasenfärbungen sind, hat Unna mit Golodetz zusammen neue Methoden ausgearbeitet, die gestatten, dem feineren Chemismus der Gewebe, speziell der Sauerstoffverteilung, nachzugehen. Für den Nachweis der Reduktion werden 3 Methoden angewandt. 1. Die Kalipermanganat-Methode: 1-2\% wässerige Lösung von $\mathrm{KMnO}_{4} 1$ Minute; Abspülen im Wasser; Alkohol, Öl, Balsam. 2. Die Eisencyan-Methode: Mischung von 1\% Lösungen von Eisenchlorid und Ferrizyankalium in Wasser zu gleichen Teilen 5 Minuten; Wasser, Alkohol etc. 3. Chrysophan-Methode: Tetranitrochrysophansäure $1 \%$ in Xylol; Xylol, Balsam. Die wichtigste ist die Permanganat-Methode, da das Bild von Säure- oder Alkaligehalt des Gewebes nicht beeinfluBt wird. Der Nachweis des Sauerstoffs beruht auf der Bläuung von Rongalitweiß (d. i. das durch Rongalit entstehende Reduktionsprodukt des Methylenblaus) bei Vorhandensein von aktivem Sauerstoff. Die Lösungen sind entweder a): Methylenblau 0,2, Rongalit 0,4, HCl $(\mathbf{2 5} \%) 4$ Tr., Wasser 10,0 oder b): Zusatz von Natronlauge $1 \%$ zur Lösung a) bis bleibende Fällung entsteht, darauf Filtration. Färbung 2-3 Minuten in einer dieser Lösungen. Ess dürfen nur frische Gefrierschnitte verwandt werden. Als Reduktionsorte erweisen sich in der Haut: glatte Muskelfasern, basale Hornschicht, Stachelschicht, Haar, Wurzelscheide, Nerven; als Sauerstofforte alle Kerne, Mastzellengranula, basale Keimschicht, Knäueldrüsenepithel, besonders der Ausführungsgänge. Aus den sehr zahlreichen Untersuchungen innerer Organe läßt sich das allgemeine biologische Gesetz ableiten: die Kerne sind die Hauptsauerstofforte des Organismus. Da aber die Oxydation nur bei Anwesenheit von Luftsauerstoff vor sich geht, so sind sie weniger als Sauerstoffansammlungen, denn als echte Katalysatoren zu betrachten, die den molekularen Luftsauerstoff zu aktivieren vermögen. Die Bindesubstanzen und das Protoplasma sind meist reduzierend, so auch das Stroma der roten Blutkörperchen, während gelöstes Hämoglobin Blaufärbung mit Rongalitweiß gibt. Wahrseheinlich sind in den Kernen stabile, gut verwahrte Fermente, die es ihnen möglich machen, durch das sauerstoffgierige Protoplasma hindurch andauernd Sauerstoff anzuziehen und festzuhalten. Die wichtigsten Oxydationsvorgänge spielen sich demnach im Kern ab und sind wahrscheinlich an ein eisenhaltiges Nucleo proteid gebunden. Falls diese Oxydationen auf einer Oxydase beruhen, so ist 
diese nach den Untersuchungen von Spitzer und Macallum als "mineralisches Ferment", als ein eisenhaltiger organischer Katalysator zu betrachten.

Die allgemein physiologischen Anschaungen, die Unna aus diesen Tatsachen ableitet, können hier nicht wiedergegeben werden. Erwähnt sei nur, da $B$ er besonders auch den Leukozyten eine sauerstoffaktivierende Fähigkeit zuschreibt und dadurch ihre Tätigkeit bei infektiösen Prozessen erklärt. Ferner können die kernreichen Ausführnngsgänge mancher Drüsen (Schweißdrüsen, Harnkanälchen) dem Endprodukt noch Sauerstoff zuführen und dadurch eine gewisse desinfektorische Wirkung verleihen, wodurch auch ihre Länge erklärt wird, die zu ihrer rein mechanischen Funktion in keinem Verhältnis steht. Sehr wichtig ist die Rolle der Mastzellen als Sauerstofforte in dem sauerstoffarmen Bindegewebe.

F. Lewandowsky (Hamburg).

Fischel, R. Hall. (Aus der Klinik Kreibich.) Der histochemische Nachweis der Peroxydase. Wiener klin. Wochenschrift. 1910. Nr. 44.

Überschichtet man einen durch Lufttrocknung fixierten Deckglasaufstrich von gonorrhoischem Eiter mit einer $2 \%$ wässerigen Lösung von benzidinmonosulfosaurem Natron, der $0.3 \% \mathrm{H}_{2} \mathrm{O}_{2}$-Lösung in einer Menge von $0.01 \mathrm{~cm}^{3}$ zugesetzt wurde, so sieht man nach kürzester Zeit eine Blanfärbung des Präparates, die sich mikroskopisch als intensiv sattblaue Färbung der Leukozytengranula auföst, während der ungefärbte Kern als weiße, ausgesparte Figur imponiert. Im Gegensatz zu den feingranulierten Leułozyten zeigen die grobgranulierten Eosinophilen eine viel dunklere, grünlichschwarze, ja braunschwarze Färbung der Granula. Die roten Blutkörperchen des Menschen reagierten von $0.5 \mathrm{~cm}^{3}$ einer $0.3 \%$ $\mathrm{H}_{2} \mathrm{O}_{2}$-Lösung angefangen mit Blaufärbung. Einen prachtvollen Anblick gewährt es, wenn man einen Aufstrich normalen Blutes der Reaktion unterwirft, bei der sich blob die feingranulierten Leukozyten färben; auf gelbem Grunde, den die roten Blutkörperchen bilden, treten die sattblauen Granula der Leukozyten in prachtvollem Kontraste hervor.

Viktor Bandler (Prag).

Jolly, J. Die Struktur und Entwicklung des Binde g ewebes. La presse méd. 1911. Nr. 2.

Jolly bespricht die Fortschritte in der Frkenntnis der Bindegewebsentstehung, seit Fle m ming 1891, die Teilung junger Bindegewebszellen des periton. pariet. von Salamanderlarven beobachtend, im Protoplasma jeder Zelle Filamente unterschied, die frei wurden, sich in Bindegewebsfibrillen umwandelten und an die Oberfläche der Zelle anlagerten. Meves hat dies kürzlich bestätigt; er nimmt mit F. filamentöse Struktur des Protoplasmas an und stellte an Sehnen, die sich in Hühnerembryonen bildeten, kurze und lange Filamente, die Mitochondren oder Chonriokonten entsprachen, erst im Innern, dann außen an der Oberfläche der Zelle haftend und nun die Reaktion von Bindegewebsfibrillen gebend, fest. Auch von anderen Forschern ist die Struktur dieser Protoplasmafilamente 
viel studiert worden. Am wichtigsten erscheinen $\mathrm{J}$ olly die Befunde von $Z \mathrm{ach}$ ari ad ès, der nachwies, daß sie nicht homogen sind, sondern aus 3 Elementen bestehen, einem Filament axile als Rest der zellulären Verlängerung im Zentrum der Fibrille, färbbar durch Methylenblau, einer (wabrscheinlich auch protoplasmatischen) peripherischen Membran und drittens, zwischen ihnen eine kollagene, i. e. durch Kochen Gelatine gebende Substanz, die wohl erst sekundär entsteht, aber die Bindegewebszfibrille vervollständigt. Das Hauptelement ist unter diesen 3 Bestandteilen der Filamente das Axile; von ihm geht Wachstum, Assimilation und auch die Bildung des Kollagens aus, es feblt niemals und kann in gewissen Fällen allein die Fibrille darstellen, während die kollagene Substanz eine sekundäre und späte Formation ist und daher nicht als Synonym mit bindegewebig gebraucht werden sollte. Jolly glaubt, daß die Arbeiten von Meves und $\mathrm{Zachariadès} \mathrm{die} \mathrm{Forschung} \mathrm{über} \mathrm{die} \mathrm{Entstehung} \mathrm{des} \mathrm{Bindegewebes}$ dem Ziele nahe gebracht haben; die filamentösen Produkte des Protoplasma dürften als Chondriokonten das primitive Material darstellen und das axile Filament ein mitochondriales Produkt sein; doch mübten weitere Studien mit nenen Techniken und an neuen Objekten noch neue Tatsachen beibringen. Münchheimer (Wiesbaden).

Pasini, A. Über die Struktur der Epidermis im normalen und pathologischen Zustande, mit spezieller Be. rücksichtigung ihrer Faserung. Unnas Dermatologische Studien (Unna, Festschrift, Bd. I). Bd. XX. p. 226.

Pasini weist in der Einleitung, die die Arbeiten über die feinere Struktur der Epidermis kurz zusammen faßt, darauf hin, daß die Ansichten der Autoren auf diesem Gebiete noch erheblich differieren. Seine eigenen Untersuchungen erfolgten mit den Metboden von Unna, Pappenheim, Krumayer u. a. und seiner eigenen Methode, die folgende ist: Härtung im Alkohol. Übertragen dünner $(2-3 \mu)$ Schnitte in eine wässerige Lösung von Phosphorwolframsäure $2 \%$ für 5 bis 10 Minuten. Kurzes Abwaschen in Aqua dest. und Übertragen für 15 bis 20 Minuten in folgende Lösung: 10 Tropfen Wasserblau-Orcein-Mischung (Grübler) + 12 Tropfen Eosin B. A. (Grübler) zu $2 \%$ in 50\%igem Alkohol + 1 Tropfen einer gesättigten wässerigen Lösung von Säurefuchsin oder Säurerubin +5 Tropfen neutrales Glyzerin. Aus dieser Farbflüssigkeit kommen die Schnitte nach kurzem Waschen in dest. Wasser sogleich in Alcohol absolutus (vorher können sie noch für einige Sekunden in die obige Lösung von Phosphorwolframsäure kommen), dann in Xylol, dann in Kanadabalsam. Diese Färbung ergibt eine klare und sichere Färbung der Epithelfaserung. Mit dieser Färbung nehmen die Filamente, das Chromatin der Kerne und das Keratohyalin eine schöne rote Färbung an, welche mit dem Blau des Zellprotoplasmas kontrastiert. Die Epithelfasern sind nur in den Interzellularräumen gefärbt. Im Stratum cylindricum und basale zeigt die untere Hälfte der Zelle äie Epithelfasern zu Bündeln vereinigt, welche die Herxheimerschen Spiralen darstellen. Aus den subtilen Untersuchungen Pasinis seien nur folgende Punkte 
kurz hervorgehoben: Die Epithelzellen der Epidermis haben eine komplizierte Struktur, die in den verschiedenen Schichten Modifikationen aufweist. Im Stratum cylindricum und spinosum haben die Zellen einen zentralen Kern und um diesen ein homogen verteiltes und retikuläres Protoplasma. P. kann der Ansicht von Ranvier nicht beipflichten, der das Protoplasma der Malpighischen Zellen bestehen läßt aus einer homogenen hyalinen Substanz, die von Filamenten durchzogen ist. Das Retikulum entspricht dem Spongioplasma von Unna. Unnas Granoplasma konnte $P$. nicht demonstrieren. Dagegen nimmt er an, daß man ein Endoplasma und ein Exoplasma unterscheiden kann und das letztere als eine Membrana limitans auffassen müsse, entsprechend der Angabe von Unna 1903. Was die Beziehungen zwischen Retikulum und Filamenten betrifft, so sind zwei Tatsachen festzuhalten: 1. Wo das zelluläre Protoplasma homogen retikulär gebildet ist, da bestehen keine intrazellulären Filamente. Wenn das Retikulum schwindet, so existieren Filamente. 2. Mit der Färbung mit polychromem Metbylenblau siebt man die Fasern des Retikulums sich in Bündeln vereinigen und jedes derselben mit einem interzellulären Filament verschmelzen. Diese morphologischen Tatsachen scheinen dafür zu sprechen, daß die Filamente vom protoplasmatischen Retikulum ausgehen. Da sie sich aber nach des Autors Methode verschieden färben, so scheint es der Fall zu sein, daß zugleich mit einer morphologischen Umwandlung des Retikulums in die Filamente eine Modifikation im Chemismus dieser Elemente vor sich geht.

Fritz Juliusberg (Posen).

Kromayer. $Z$ ur Frage dernormalen Desmoplasie. Unnas Dermatologische Studien (Unna-Festschrift, Bd. I) Bd. XX. p. 417.

Kromayer weist auf die Ansicht Unnas hin, da $B$ bei den weichen Naevis der Haut aus dem epithelialen Zuammenhange sich Zellkomplexe loslösen, um ins Bindegewebe verlagert $z u$ werden und dort den histologischen Hauptbestandteil der Naevi zu bilden. Als Unna in seiner Arbeit: Naevi und Naevokarzinome (Berl. klin. Woch. 1893) diese Ansicht äußerte, widersprach sie den Vermutungen Kromayers, der diese Zellkomplexe als bindegewebiger Natur auffaßte und der allgemein herrschenden Ansicht beipflichtete, daß eine Umwandlung von Epithelzellen in Bindegewebszellen unmöglich sei. Heute ist $\mathrm{Kromayer} \mathrm{der} \mathrm{Ansicht,}$ daB es eine Desmoplasie der Epithelzellen, d. $h$, eine Umwandlung der Epithelzellen in Bindegewebszellen, in der Tat gäbe. Er hat schon früher Material zu dieser Frage bearbeitet; in der vorliegerden Arbeit beschäftigt er sich mit Vorgängen, die sich an der Lippenrotgrenze Neugeborener finden. Dort ließ sich in drei Fällen, wo die äußere Haut an die Schleimhaut stößt, eine verwischte Grenze konstatieren, wo ein unregelmäßiges Durcheinander von Epithel- und Bindegewebszellen auffällt. Der Raum, auf dem diese Veränderungen sich finden, entspricht etwa der Ausdehnung von 4-10 Papillen der äußeren Haut, ist also eng begreazt. Hier findet nach der Ansicht des Verfassers eine stürmische Umwandlung von Epithel und Bindegewebe statt, viel stürmischer als in den weichen 
Naevis. An diesem Objekte glaubt Kromayer nachweisen zu können, daß eine Desmoplasie nicht geleugnet werden kann.

Fritz Juliusberg (Posen).

Zuelzer, G. Über Hormone. Folia Serologica. Bd. VI. H. 2. 1910.

Zusammenfassender Bericht über den gegenwärtigen Stand unserer Kenntnisse von den Hormonen. Meirowsky (Cöln).

Godoletz, L. Über Färbungen mit "Nichtfarbstoffen". Unnas Dermatologische Studien (Unna-Festschrift, Bd. I). Bd. XX. pag. 472 .

Godoletz weist auf Unnas Arbeiten über den Gebrauch ungefärbter chemischer Reagentien in der Histologie. Er selbst hat gemeinsam mit Unn a über diese Methoden berichtet (Unn as Monatshefte 1908/1910). In folgendem unterzieht er diese Methoden, teilweise abgeändert, einer kritischen Darstellung.

Man kann sie in drei Gruppen einteilen; in Färbungen, die das Reduktionsvermögen der Gewebe anzeigen, in solche, die einen Gehalt der Gewebe an bestimmten Stoffen ermitteln, und in solche, die eine besondere Affinität zu bestimmten Substanzen feststellen.

Reduktionsfärbungen sind die Kaliumpermangat-Methode, die mit einer $1-2 \%$ igen $\mathrm{KMnO}_{4}$-Lösung auggeführt wird, die Eisencyan-Methode, bei der man die Schnitte in einer Mischung von gleichen Teilen je einer $1 \%$ igen Lösung von Eisenchlorid und Ferricyankalium 10 bis 15 Minuten beläßt, und die Tetranitrochrysophansäure-Methode (bei dieser kommen die Schnitte aus Alkohol in Alkoholäther und von da durch reines Xylol in eine $1 \%$ ige Lösung der Substanz in Xylol, wo sie 5 Minuten bleiben, dann in Xylol).

Reaktionsfärbungen werden gemacht auf Tyrosin und auf Cholesterin. $\mathrm{Zu}$ dem ersten $\mathrm{Z}$ wecke dient ein verdünntes Millons Reagenz. Für den Nachweis des Cholesterins kommt eine Mischung auf Schwefelsäure und Formaldehyd in Betracht.

Bei den Affinitätsfärbungen werden die Gewebsschnitte nacheinander mit zwei Substanzen behandelt; die zusammen eine gefärbte Verbindung bilden.

Bisher wurden die Färbungen nur an Fußsohlenschnitten gemacht. Bei dieser ergaben die Methoden zunächst einen sehr scharfen Gegensatz zwischen Hornschicht und Kutis. Sowohl bei den Reduktionsfärbungen, wie bei den Affinitätsfärbungen verhalten sich die beiden Hauptbestandteile der Haut völlig konträr; die Hornschicht reduziert energisch und hat eine Affinität zu einer Reihe von Salzen der Schwermetalle, die sie zu binden vermag, während die Kutis weder Reduktionsvermögen noch Affinität zu Metallsalzen aufweist. Die Kerne sind bei allen Färbungsmethoden ungefärbt. Fritz Juli usberg (Posen).

Pappenheim, A. Drei neue Färbemethoden für Paraffinschnitte. Unnas Dermatologische Studien (Unna-Festschrift, Bd. II). Bd. XXI. p. 305 . 
Pappenheim berichtet über drei Färbemethoden, die den Vorzug vor der sukzessiven Methylenblau-Orcein-Methode Unnas und vor der sukzessiven Toluidinblau-Eosin-Orange-Methode Dominicis besitzen, dab sie differentielle Kombinationsfärbungen simultaner Natur sind. Der Autor hat für diese Färbungen seine kombinierte May-Giemsa-Färbung (of. Med. Klinik, 1908, Nr. 32) folgendermaßen gestaltet: Vorfärben der aufgeklebten Paraffunschnitte in einer wasserverdünnten $M a y-G r u ̈ n-$ wald-Lösung etwa $1 / 2$ Stunde im Brutschrank. Herausnehmen und ohne Abspülen einlegen in eine wasserverdünnte Giemsa-Lösung (6 Tropfen Giemsa-Lösung neue Vorschrift auf $10 \mathrm{ccm}$ Wasser) eine Stunde lang im Brutschrank. Gutes Abwaschen im Wasser.

Von hier ab kann in dreifacher Weise verfahren werden. Für das 1. Verfahren darf keine Chromfixierung vorausgehen, sondern es muß fixiert werden in Alc. abs., Formol, Sublimat oder Kombinationsmischungen dieser Fixative, für das 2. und 3. Verfahren können auch Chromatfixative verwendet werden. (P. empfiehlt Helly sche Fixation: $Z$ enker + Formol ohne Essigsäure und Orths Fixation: Müller + Formol.)

Verfahren 1: Nach dem Abwaschen: Entwässern in Aceton puriss. (Kahlbau m), Aufhellen in Terpentin und Einbetten in Terpentinbalsam.

Verfahren 2: Differenzieren in essigsaurem Wasser nach $\mathrm{F}$ is cher und zwar 6 Tropfen Eisessig anf 100 Wasser. Gut auswaschen in dest. Wasser, Ablaufenlassen des überschüssigen Wassers vom Deckgläschen durch Aufstellen mit der Kante auf Fließpapier. Vom Objektträger Entfernen des Wasserüberschusses durch Abwischen der Rückseite und der Seitenteile des Objektträgers. Alsdann kurzes Einlegen des Schnittes zum schnellen Entwässern (nur kurze Zeit eintauchen, etwa ein- bis zweimal bin- und herschwenken) in einer Mischung von 7 Teilen Alc. absolut., 2 Teilen Methylalcohol absolut, und 1 Teil Aceton puriss. Frischer Alc. abs., Xylol, neutraler Xylolbalsam in Dammarlack.

Verfahren 3: Einlegen in $30 \%$ ige wässerige Tanninlösung, die auf 100 Teile 20 Tropfen Eisessig enthält, 1 Minute. Dann langes gründliches Abwaschen in Wasser, 5 Minuten. 70\%iger Alkohol. Absoluter Alkobol. Xylol. Balsam. Fritz Juliusberg (Posen).

Wolbach, S. B. Der Gebrauch von Kolophonium zur Differenzierung des Kosinmethylenblaus und anderer Farben. The Journal of the Americ. Med. Association. 1911. Februar 4. pag. 345 .

Wie Wolbach ausführt, besteht die Eosinmethylenblaufärbung (Mallory und Wright: Pathological Technic. 1908) darin, daß mit Eosin und dann mit alkalischem Methylenblau überfärbt wird, worauf eine Differenzierung mit $95 \%$ igem Alkohol folgt. So ist diese Färbung nur in nach $Z \in n k e r$ fixiertem Material verwendbar. Für diese Färbung erwies sich nun der Zusatz von Kolophonium zur Differenzierungsflüssigkeit als sehr brauchbar. Dadurch ist die Methode auch für in Formaldehyd oder Alkohol fixiertes Material anwendbar geworden. Die besten Resultate ergab ein Zusatz von $0.75-1.5 \%$ Kolophonium auf das Gewicht 
des Alkohols. Je stärker der Zusatz von Kolophonium zum Alkohol ist, umso intensiver färbt das Eosin. Für die Differenzierung von in Alkohol oder Formaldehyd fixiertem Gewebe muß der Zusatz des Kolophoniums $10 \%$ au $/ \mathrm{s}$ Gewicht betragen. Für die Färbung Gra m-negativer Bakterien bei mit Formaldehyd fixiertem Gewebe ist eine 10\% ige Lösung von Kolophonium in Azeton besser, als eine entsprechende in Alkohol. Bei der Differenzierung mit Kolophonium, sei es in Lösungen mit Alkohol oder mit Azeton, müssen die Schnitte aus dem Wasser direkt in die Lösung gebracht werden. Nach vollendeter Differenzierung folgt kurzer Aufenthalt in Alcohol absolutus, dann Xylol. Worauf die Wirkung des Kolophoniums beruht, kann Autor nicht angeben. Eine weitere Anwendung der Kolophoniummethode ist die zur Differenzierung von Schnitten, die nach $G$ i e m sa gefärbt sind. An Stelle der Mischung von Xylol und Azeton, die Gi ems a empfiehlt, nimmt man eine $20 \%$ ige Lösung von Kolophonium in Azeton. Nach dem Differenzieren folgt kurzes Waschen in einer $5 \%$ igen Lösung von Xylol in Azeton, dann Aufhellen in Xylol und Montieren in Zedernholzöl. Auch für dje Gramsche Methode erweist sich das Kolophonium als vorteilhaft, da eine 5-10\% ige Kolophonium-Alkohol-Mischung besser entfärbt als reiner Alkohol und doch die Bakterien tiefblau läßt. Sie wirkt nicht so energisch wie Anilinöl, aber gibt konstantere Resultate. Fritz Juliusberg (Posen).

Liesegang, Raphael. Zur Kolloidchemie der Haut. Unnas Dermatologische Studien (Unna-Festschrift, Bd. III). Bd. XXI. p. 168.

Die interessanten Ausführungen Liesegangs sind nicht zum kurzen Referat geeignet. Fritz Julius berg (Posen).

\section{Bildungsanomalien.}

Jaeger, A. Frankfurt a. M. Die Ursache der Krebserkran kung. Wiener klinische Wochenschr. 1910. Nr. 50.

Die Tumoren stellen nach des Autors Ansicht eine intrazelluläre Stoffwechselerkrankung dar, die dadurch, daß sie mit ihrer funktionellen Zelldestruktion gerade den organogenetisch festgelegten Zellcharakter in seiner spezifischen Differenzierung trifft, von neuem das Organgeschehen der Ontogenese aktiviert und nur eine Atypie erfährt. Die Gutartigkeit oder Bösartigkeit eines Tumors ist lediglich der Ausdruck einer geringeren oder tiefgreifenden Intensität jener Abartung in der Molekularstruktur der jeweils spezifischen Zellorganisation. Der Autor stimmt der Anschauung A lbrechts voll zu, welche besagt, daß Tumorbildung und Organbildung im Wesen analoge Lebenserscheinungen darstellen. Als bewiesen erachtet der Autor ferner den Kausalnexus zwischen der spezifischen Funktionssphäre und der Proliferationssphäre der Zelle, insofern der Wandel in der stofflichen Konstitution der ersteren den Mechanismus der letzteren aus- 
löst. Der Autor bestreitet mit Entschiedenheit, daß der Krebs oine infektiöse Erkrankung darstellt. Die Krebszelle hat ihren Ausgang von normalen Zellen des Organismus genommen, indem die letzteren speziell in ihrem spezifischen Stoffwechselgetriebe entarten. Lediglich aus diesem Vorgang leiten sich die auslösenden Kräfte selbständiger Zellwucherung, der Krebswucherung her.

Viktor Bandler (Prag).

Hertzler, Arthur. Die Ätiologie der Epitheliome. The Journal of the Americ. Med. Association. 1910. Dezember 31. pag. 2290.

Hertzler kommt in seinen Untersuchungen über die Ätiologie der Epitheliome zu folgenden Schlüssen: 1. Die Bildung von Fibrin ist der erste Schritt bei der Bildung von Bindegewebe. 2. das Epithel entwickelt sich nur bei Anwesenheit von Fibrin. 3. Bei der künstlichen Produktion von Epithel durch Sudan III. finden die ersten Veränderungen im subepithelialen Bindegewebe statt. 4. Bei Röntgenkarzinom kommt es zuerst zu Verānderungen im Bindegewebe, die tinktoriell mit denen identisch sind, welche man bei den Experimenten mit Sudan konstatiert. 5. Die Veränderungen im Bindegewebe beim beginnenenden Epitheliom sind tinktoriell identisch mit denen bei Röntgenkarzinom und mit denen bei den Experimenten mit Sudan. 6. Der konstanteste Faktor bei der Krebsentstehung ist die chronische Irritation. Chronische Irritation bringt die eben erwähnten Veränderungen hervor. 7. Die Folgen der eben aufgezählten Phänomene führen zu der Arbeitshypothese, daß die Ätiologie des Karzinoms vergesellschaftigt ist mit verminderten azidophilen Figenschaften des Bindegewebes, wobei es sich dem Fibrin in seiner färberischen Reaktion nähert. Fritz Juliusberg (Posen).

Gould, Alfred Pearce. Über Karzinom (Bradshaw Lecture). The Laucet. 1910 Dezember 10. pag. 1665.

Ausfübrliche Vorlesung über die Ergebnisse der Karzinomforschung, nicht zam Referat geeignet. Fritz Juliusberg (Posen).

Veress von, Franz. Über das Verhältnis des Cornu cutaneum zum Hautkrebs. Unnas Dermatologische Studien (Unna Festschrift Bd. I). Band XX. pag. 401.

Nach Bericht über zwei einschlägige Fälle kommt v. Veress zu folgenden Schlüssen über die Bezithungen des Cornu cutaneum zum Hautkrebs:

Das echte Hauthorn (unter echtem Hauthorn versteht man Geschwülste von papillärem Bau, die in ihren Hornkörper sog. Marksubstanz enthalten, im Gegensatz zu den nur aus Hornmasse bestehenden, nicht papillären und der Marksubstanz entbehrenden einfachen Keratomen) ähnelt in seiner Ätiologie dem Hautkrebs. Beide Geschwülste kommen hauptsächlich bei älteren Personen vor und bevorzugen die gleichen Körperteile.

Bei der Entstebung beider können vorangegangene lokale Reize, Verletzungen, Narben eine Rolle spielen. Bei dem einen wie bei dem andern können senile Keratome (z. B. Asmus, Dubreuilhs und ein Fall des Autors), Papillome, Verrucae usw. als Ausgangspunkt dienen. Arch. f. Dermat. u. Syph. Bd. CIX. 
An der Basis beider Geschwülste finden sich in der Regel die gleichen Veränderungen des Bindegewebes, nämlich Proliferation und Infiltration mit Lymphozyten, Leukozyten und Plasmazellen.

Zieht man die Ähnlichkeit ihrer Ätiologie, Struktur und Topographie in Betracht, so wird es verständlich finden müssen, daß sich manchmal sehr leicht aus dem einen das andere entwickelt, in der Weise, daß auf Hantkrebs ein Hautborn entsteht oder das letztere karzinomatös degeneriert. Von diesen beiden Möglichkeiten ist wahrscheinlich die letztere häufiger.

Fritz Juliusberg (Posen).

Wechselmann, W. Über osteomalazische Veränderungen bei Neurofibromatose. Unnas Dermatologische Studien (Unna Festschrift Bd. I). Band XX. pag. 133.

Bei einem Patienten mit ausgesprochener Neurofibromatose fand Wechselmann folgende Knochenveränderungen: Eine sehr beträchtliche Kyphoskoliose mit der Konvexität nach rechts, eine mäßige Lordose der Lendenwirbelsäule; die Rippen des Brustkorbes sind verbogen und der Ansatz der linken unteren Rippen am Sternum springt stark winklig vor. Das rechte Schulterblatt ist kleiner and schmäler wie das linke. Die Skoliosa ist nach einem Fall im 10. Lebensjabr entstanden. Der Autor referiert eingehend die Literatur über Knochenveränderungen bei Neurofibromatose. Fritz Juliusberg (Posen).

Blaschko, A. Das Hydrocystoma papilliferum, ein Beitrag zur Lehrevon den Schwejßdrüsengeschwülsten. Unnas Dermatologische Studien (Unna-Festschrift. Bd. II. Band XXI), pag. 560 .

Blaschko unterscheidet vier Typen der Schweißdrüsentumoren: 1. Das Syringozystadenom. 2. Das Adenoma hidradenoides tubulare vulvae (P i c k), einzeln oder multipel auftretend, an den kleinen oder großen Labien sitzende Tumoren, die mikroskopisch scharf gegen das Gesunde abgesetzt, einen lobulären Aufbau mit keilförmigen Septen, solide adenomatöse und multilokuläre, unregelmäßig zystische Abschnitte zeigen. 3. Den Naevus syringadenomatosus (Petersen. Wolters), bei dem von der Oberfläche Epithelfortsätze in die Tiefe ziehen, die entweder nach kurzem Verlaufe mit kolbenförmiger Anschwellung enden oder sich vielfach verzweigen, so daß hirschgeweihartige Formen entstehen. 4. Eine Abart dieser Naevi, ein Fall von Elliot bezeichnet als Adenocystoma intracanaliculare und ein Fall von Bartel beschrieben als Cystadenoma papilliferum der Schweißdrüsenausgänge. Zu dieser letzten Gruppe gehört der von B las chk o beschriebene Fall, der eine Geschwulst auf dem Scheitelwirbel eines 10jährigen Knaben betrifft. Die etwa $3 \mathrm{~mm}$ prominente Geschwulst ist etwa zehnpfenniggroß. Auf dem Durchschnitt weist sie Zysten bis $1 / 2 \mathrm{~mm}$ Durchmesser auf. Sie zeigt nirgends eine scharfe Begrenzung. In ihrem Bereich fehlen Haare, Talgdrüsen nnd normale Schweißdrüsen. Die größeren Zysten sind regelmäßig oval, die kleineren sind unregelmäbig schlauchförmig und zeigen in ibrer gegenseitigen Lage noch deutlich die Anordnung der normalen SchweißdrüsenknäuelAn vielen Stellen ragen die bindegewebigen Septa papillenartig in das 
Jumen der Zysten hinein. Der Epithelbelag der Zysten ist nicht überall gleich: an einigen Stellen findet sich palisadenförmiges Zylinderepithel, an anderen ist das Epithel kabisch, an anderen plattgedrückt. Wo die Zylinderzellen deutlich sind, erkennt man unter ihnen die Kerne der subepithelialen Muskelschicht, nach außen eine Membrana propria. Die Zysten öfnen sich immer zwischen zwei Zotten; diese stellen also das zwischen den Zysten liegende ausgesparte Gewebe dar. Hier wird der Epitelbelag massig und wuchernd und überzieht die Ausführungsgänge der Zysten in vielfacher Schicht. Fritz Juliusberg (Posen).

Hirschel. Die klinische Bedeutung des sogenannten Pagetschen Brustkrebses (Krebsekzem der Brust). München. mediz. Wochenschrift. 1910. Nr. 50.

An der Hand zweier Fälle von Pagetschem Brustkrebs weist Hirschel darauf hin, jedes chronische Ekzem der Brustwarze und des Warzenhofes möglichst sorgfältig zu beobachten und bei unsicherer Diagnose eine Probeexzision auszufübren, da event. schon ein kleines Mammakarzinom besteht, das sekundär das Ekzem verursacht.

Oskar Müller (Recklinghausen).

Caird, F. M. Das Epitheliom der Zunge. Eine Übersicht über 60 Spitalsfälle. The Edinburgh Med. Journ. Jan. 1911.

Enthält nichts Neues.

Wilhelm Balban (Wien).

Moberg, Ludwig. Ein Fall von solitärem Dermatomyom. Unnas Dermatogische Studien. (Unnas Festschrift. Bd. II). Band XXI. pag. 138.

Moberg weist darauf hin, daß man nach Besniers Einteilung zu unterscheiden hat zwischen "Myômes simples" oder „Dermatomyomes proprement dits", die in der Regel multipel auftreten, von denen bisher 22 Fälle publiziert sind und den meist solitären "Myômes dartoiques", die von präexistierenden Muskellagern ausgehen. Bei der eigenen Beobachtung Mobergs handelt es sich um einen solitären Tumor von der Wade einer 23jährigen Fran von $5 \mathrm{~mm}$ Länge, $3 \mathrm{~mm}$ Breite und 2 bis $3 \mathrm{~mm}$ Dicke, der aber zu dem Myomes simples gehört. Der Tumor besteht aus glatten Muskelzellen, die einander in dickeren oder dünneren Bündeln nach allen Richtungen kreuzen. Die Muskelkerne sind langgestreckt zylindriscb und durchschnittlich 20 bis $30 "$ lang. Charakteristich für die Myome ist die Schmerzhaftigkeit, die auch in diesem Falle vorhanden war. Diese wird verschieden erklärt. Unna erklärt sie durch die abnorme Spannung einiger Nervenäste, die durch die sie vergrößernde Geschwulst verursacht wird. Die Arbeit bringt die vollständige Literatur der Hautmyome. $\quad$ Fritz Juliusberg (Posen).

Fick, Johannes. Zwei relativ seltene Haut umoren. Unnas Dermatologische Studien (Unna Festschrift. Bd. I.) Band XX. pag. 277. Seinen ersten Fall bezeichnet Fick als ,ossifizierenden Tumor im Korium". Es bandelt sich um einen Tumor von der Größe einer halben Erbse von der Hand einer 36jährigen Patientin. Es fand sich, wie die eingehende Beschreibung ergibt, um eine Ossifikation in einem Tumor, 
der den Fibromen nahe stebt, aber doch auch Unterschiede von diesen aufweist; auch das nicht ossifizierte $Z$ wischengewebe zeigt ein morphologisch anderes kollagenes Gewebe, wie die Fibrome und ferner spricht gegen Fibrom die ausgesprochene Trennung von zellreichen und zellarmen Territorien. Da das ausgebildete Knochengewebe gegenüber den Osteoiden sehr zurücktritt, wäre auch die Bezeichnung Osteom nicht am Platze. Der Fall bietet viele Analogie mit einem Tumor der Brustdrüse, über den St. Arnold in Virchows Arehiv Bd. 148 berichtet hat.

Seinen zweiten Tumor bezeichnet $\mathrm{Fick}$ in Anlehnung an die von L. Pick vorgeschlagene Nomenklatur als Adenoma hidradenoides. Die etwa erbsengroße Geschwulst stammt von der Wange eines 60jährigen Individuums. Der Tumor bestand aus einem bindewebigen Stroma und epithelialem Parenchym. Die Epitbelienzellen stellen Auskleidungszellen eines oder mehrerer Schläuche dar, der an zwei Stellen zystisch erweitert und zum Knäuel zusammengerollt ist. Das Epithel setzt sich gegen das Stroma scharf ab, wobei die elastischen Fasern unter dem Epithel an vielen Stellen eine sehr gut ausgebildete Membrana limitans bilden. Die Anordnung der Epithelzellen ist eine drüsenzellengleiche, so daß die Bezeichnung Adenom gerechtfertigt ist und zwar handelt es sich um ein Adenom, dessen Zellen mit den Zellen des normalen Schweißdrüsenknäuels morphologisch die weitest gehende Ähnlichkeit zeigen. Spezielle Schwierigkeit machte die Differentialdiagnose des Tumors gegen die sog. Basalzellenepitheliome. Bei diesen kommt es aber wohl zur Bildung von Hohlräumen, nie aber zur Ausbildung der einer bestimmten Drüse entsprechenden Architektur und Zellstruktur. Der vorliegende Tumor charakterisiert sich vor allem, auch gegenüber den gewöhnlichen drüsenähnlichen Epitheliomen durch die in einer ganz bestimmten Richtung fortgeschrittene Differenzierung der Epithelzellen, sowohl in ibrem morphologischen Verhalten, wie in dem gegenseitigen Verhalten von Epithel und Bindegewebe (Membrana propria). Fritz Juliusberg (Posen).

Dependorf, Th. Über das A uftreten von Epithelzysten in dem Zahnfleisch von Säuglingen. Unnas Dermatologische Studien (Unn a Festschrift, Bd. II). Band. XXI. pag. $6 \pm 6$.

Dependorf beschäftigt sich in dieser Arbeit mit den Epithelzysten an den vorderen Teilen der Kiefer, des Ober- und Unterkiefers, wie sie Epstein schon am harten Gaumen beschrieben und als verhornte Epithelperlen nachgewiesen hat. Sie treten nicht immer als makroskopisch sichtbare Knötchen hervor, sondern sind auch dort vorhanden, wo äußere Tumoren fehlen. Geht das Aufplatzen und Freilegen der Epithelzysten unter entzündlichen Erscheinungen vor sich, so können Verwechslungen mit Aphthen und anderen ulzerösen Prozessen vorkommen. Aus den sorgfältigen Untersuchungen des Autors geht hervor, daß diese Epithelperlen auf mannigfache Weise entstehen können. „Nicht nur kann durch direkte Verlängerung einzelner Epitheleinstülpungen eine kolbenartige Anschwellung nach Art der Schmelgleiste entstehen, aus der sich durch Abschnürung eine Schichtungskugel bildet, sondern auch rudimen- 
täre Epithelleisten, wie die Zahnleiste und Ausführungsgänge reduzierter Drüsen sind in der Lage, durch Zerfall sich in Schichtungskugeln und Epithelperlen umzuwandeln. Jede Faltung des Epithels im Bindegewebe, jede Einstülpung des Epithels ist im stande, derartige Epithelzellen hervorzurufen."

Fritz Juliusberg (Posen).

Castorina San Filippo, G. Beitrag zum Studium der Struktur und Pathogenese der Atherome. Bull. d. Scienze med. Heft 12. 1910.

A. klassifiziert die Atherome nach der Summe der klinischen Charaktere und histologischen Eigentümlichkeiten nicht unter die wirklichen, sondern unter die scheinbaren Tumoren. Ihr Ursprung ist, anstatt auf eine fötale Invagination - wie die embryonale Theorie möchte - auf die Retention von Sekret in einer Talgdrüse infolge Verschluß des Austührungsganges zarückzuführen.

J. Ullmann (Rom).

Santantonio, U. Untersuchungen über das elastische Gewebe in den Tumoren. Giorn. int. d. Scienze med. Heft 22. 1910.

Aus den Untersuchungen Santantonios geht hervor:

1. In den Fibromen findet man kaum Neubildung von elastischem Gewebe. Seine Abwesenheit in Massen neugebildeten Gewebes ist vor allem evident bei den Fibromyomen des Uterus.

2. Bei den Enchondromen beobacbtet man keine elastischen Fasern. Dagegen fanden sich neugebildete elastische Fasern bei einem Lipom und bei Angiomen.

3. Bei Adenomen, Epitheliomen fanden sich neugebildete elastische Fasern, nicht aber bei Karzinomen (von denen allerdings nur eine kleine Zahl untersucht wurde).

4. Im Stroma der Sarkome ist die Existenz neugebildeter elastischer Fasern ein fast konstantes and allgemeines Faktum.

5. Bei Lipomen fehlen in der Regel die elastischen Fasern.

6. Bei Angiomen ist Hyperproduktion el. F.

7. Bei Mykomen sind keine el. F.

8. Bei Endotheliomen sind reichliche elastische Fasern vorhanden im Bindegewebe, welches das Stroma des Tumors bildet, wenige Fasern dagegen findet man in den neoplastischen Massen.

$$
\text { J. Ullmann (Rom). }
$$

Leon, M. Ein Fall von Haarzunge. The Journal of the Americ. Med. Association. 1910. Dez. 24. pag. 2233.

Kurze Mitteilung eines Falles von Haarzunge, die nach Behandlung mit Wasserstoffsuperoxyd und anderen Antisepticis abheilte.

$$
\text { Fritz Juliusberg (Posen). }
$$

Aschoff, L. Zur Frage der Cholesterinesterverfettung beim Menschen. Unnas Dermatologische Studien (Unna Festschrift. Bd. II). Band XXI. pag. 23.

Asch of $f$ hat schon früher ( $\mathrm{Zi}$ ieglers Beiträge 1909. B. 47) betont, daß wir bei den Verfettungen 2 große Gruppen zu unterscheiden haben, die Glyzerinesterverfettung und die Cholesterinesterverfettung. Letztere 
umfaßt die Mehrzahl der Störungen des Lipoidstoffwechsels, die man als myeline Degeneration, Protagondegeneration etc. bezeichnet hatte. Ka iserling und Orgler haben durch den Nachweis der Doppelbrechung bestimmter fettähnlicher Tropfen die Frage angeschnitten. Im AnschluB an die Cholesterinesterverfettung in Nieren, bei der Arteriosklerose etc. kommt der Autor auf die Xanthome zu sprechen. Aschoff unterscheidet 1. die Xanthomgeschwülste, die echten Xanthome, 2. die Xanthelasmen, 3. die xanthomatösen Degenerationen. Die ersten beiden Gruppen sind zusammengesetzt durch die Xanthornzellen. Die erste Gruppe, die echten Xanthome sind zu trennen in die reinen Xanthome, z. B. die Geschwülste an den Augenlidern und die xanthomatösen Mischgeschwülste, die besonders an den Phalangen beobachtet werden. Ein Fall letzterer Art wird angeführt. Die Xanthelasmen sind charakterisiert durch das infil. trative Auftreten von echten Xanthomzellen in den Spalten der Kutis, die xanthomatosen Degenerationen dadurch, daß in Geschwülsten, entzündlichen Granulationen, entzündlich veränderten Organen charakteristische Xanthomzellen auftreten. Die Untersuchungen von Störk und Panzer haben für die Xanthomgeschwulst, die von $P i c k, P i n k u s$ und Pringsheim für alle xanthomatösen Bildungen den exakten Nachweis gebracht, daß das in den Xanthomen und Xanthelasmen vorhandene Fett aus Cholesterinester besteht. Die Xanthomzelle ist nach Pick und Pinkus nichts anderes als eine cholesterinfetthaltige Bindegewebs- oder Endothelzelle. (Deutsche med. Woch. 1908, 33 und 1909, 49). Die Untersuchungen von $\mathrm{Pick}$ und $\mathrm{Pinkus,}$, denen sich der Autor anschlieBt, haben die verschiedenen Formen der Xanthome und xanthomatösen Degenerationen erklärt. Das Augenlidxanthom ist eine lokale Gewebsmißbildung, wobei die Bindegewebszellen Cholesterinfettsäureester speichern. Das generalisierte Xanthom ist die Folge einer Cholesterinämie, welche zur Ablagerung des Cholesterinesters in den Kutiszellen führt. Bei der xanthomatösen Degeneration handelt es sich um eine lokale, durch entzündliche Exsudation bedingte Infiltration mit Cholesterinester oder um Resorption frei werdender Cholesterinester. Durch Resorption dieser Substanz entstehen die Pi ckschen Resorptionsstrukturen, die typischen Xanthomzellen.

$$
\text { Fritz Juliusberg (Posen). }
$$

Buschke, A. Die Übertragung von Rattensarkom und Mäusekarzinom a u neugeborene Tiere. Berlin. Klin. Wochenschr. 1911. Nr. 5. p. 215.

Der Verfasser hat eine Reibe interessanter Impfungen an Ratten und Mäusen ausgeführt. Er kommt zu dem Resultat, daß sowohl die sogenannten sarkomatösen, wie die epitheliomatösen Thiergeschwülste auf neugeborene Tiere in den ersten Lebenstagen gut übertragbar sind, daß der Organismus der neugeborenen Tiere anscheinend einen sehr guten Nährboden für das Wachstum der Geschwülste abgibt, daß die Entwicklung der Tumoren allem Anscheine nach ebenso wie bei den erwachsenen Tieren vor sich geht, und bei den sarkomatösen Tumoren, die daraufhin 
untersucht wurden, Immunitätserscheinungen nicht konstatiert werden konnten.

Ho ebne (Frankfurt a. M.).

\section{Akute und chronische Infektionskrankheiten.}

Leber, A. und v. Prowazek, S. Über eine neue infektiöse Bindehauterkrankung. Berl, klin. Wochenschr. 1911. Nr. 5. p. 217.

Ausführliche Beschreibung der von den Verfassern Epitheliosisdesquamativa genannten, besonders auf den Samoainseln vorkommenden Krankheit. Die Arbeit eignet sich nicht zu kurzem Referat, sie muß im Original nachgelesen werden. Hoehne (Frankfurt a. M.).

Nicolle. Recherches expérimentales sur le Typhus exanthématique entreprises à l'institut Pasteur de Tunis pendant l'année 1910. (Deuxième mémoire.) Annales de l'Institut. Pasteur. Nr. 1. Janvier 1911.

Durch zahlreiche Experimente findet Nicolle, daß alle Affen, auch die der neuen Welt, für das Virus des Typhus exanthematicus empfänglich sivd. Die Impfung erfolgt durch Injektion von 4-5 $\mathrm{cm}^{8}$ Blut in die Bauchhöble des Tieres. Die größte Zahl der Experimente wurde am Macacus sinicus angestellt. Die Inkubation dauert in der Regel 3-4 Tage, dann allgemeine Symptome wie Appetitlosigkeit, Traurigkeit und schlieblich bricht das Fieber aus, das das Hauptsymptom des Affentyphus ist. Die Fieberperiode dauert von 5-14 Tage, rascher Anstieg bis zu 40 und $41^{\circ}$, dann Schwankung, höhere Konstanz und schließlich ziemlich rascher Abfall.

Durch Passage schwächt sich das Virus nicht ab. Während der Fieberperiode ist das Blut immer virulent, und zwar um so mebr, je näher man dem Tage der Entfieberung ist.

Nach schwerer Infektion durch die erste Impfung erhält man volle Immunität; inkonstante Resultate bei schwächerer Erkrankung; keine Immunität erzielt man durch Flohstiche oder durch Impfung mit auf $50^{\circ}$ erhitztem Blut oder nach Impfung ohne Effekt.

Im Serum sind präventive und kurative Stoffe enthalten, wenn es von genesenen Menschen und Affen 10 bis 12 Tage nach der Heilung entnommen wird. Man soll sich nur des filtrierten Serums bedienen; man muß mit mindestens $20 \mathrm{~cm}^{3}$ Serum beginnen und die Dosen wiederholen.

M. Oppenheim (Wien).

Nicolle, Conor et Conseil. Recherches expérimentales sur le Typhus exanthématique, entreprises à l'institut Pasteur de Tunis pendant l'anné 1910. Annales de l'institut Pasteur. Tome XXV. Nr. 2. 25. Februar 1911. Fortsetzung und Schluß. Die endgültigen SchluBsätze $\mathrm{Nicolles}$ gipfeln in folgendem: 
Der Typhus exanthematicus ist vom Menschen auf Schimpansen und Makaken überimpfbar. Zur Überimpfung darf man nur vollständig gesunde Exemplare nehmen. Der Schimpanse ist viel empfindlicher dem Virus gegenüber als der Makakus; für den ersteren genügt zur sicheren Infektion $1 \mathrm{~cm}^{8}$ menschliches Blut, subkutan injiziert, für den letzteren 4-5 $\mathrm{cm}^{\mathrm{g}}$, aber intraperitoneal appliziert.

Die Virulenz des Blutes scheint gegen das Ende der fieberhaften Periode zuzunehmen; ebenso für Makaken durch die Passage durch den Schimpansen.

Die Klinik des experimentellen Typhus ist bei den verschiedenen Affenarten gleich und ähnlich dem menschlichen Typus.

Die Affenpassage ist unbegrenzt oft möglich. Nach schwerer Infektion bekommen die Affen volle Immunität; eine leichte und abortive Attacke macht nicht sicher Immunität.

Das Blut der Genesenden hat sowohl präventive als als auch kurative Eigenschaften; dies dürfte die Basis für eine Behandlungsmethode des Typhus exanthematicus abgeben. Man darf vermuten, daß der Erreger des $T$. e. ein intrazellulärer ist. Der Virus wird durch 50-55 Wärme zerstört.

Der Überträger der Krankbeit ist der Flob. Dieser kann die Krankheit nur zwischen dem 5. und 7. Tag nach dessen Aufsaugung des Blutes durch Stich übertragen; dadurch ist es wahrscheinlich, daß das Virus des Typhus exanthematicus im Flohkörper eine besondere Entwicklung durchmacht. Dex Floh kann sich nicht nur infizieren während der Krankheit, sondern auch zwei Tage vor und zwei Tage nach dem Fieber, weil das Blut auch zu dieser Zeit noch infektiös ist.

Das Serum der Exanthemathiker enthält oft ein aktives Agglutinine gegenüber dem Micrococcus melitensis.

Auch Kinder können am Typhus exanthematicus erkranken; die Erkrankung ist sehr gutartig; die Ammen sind sehr resistent. Es ist sehr schwierig, den Typhus exanthematicus von den eruptiven Formen des Paludismus zu unterscheiden. M. Oppenheim (Wien).

Weill, E. et Mouriquard, G. My okarditis und plötzlicher Tod bei Scharlach. La presse méd. 1911. Nr. 3.

Plötzlicher Tod bei Scharlach wird zumeist auf Nervensystem-, Nebennieren- oder andere Erkrankungen zurückgeführt. Die Verf. fanden bei der Obduktion in einem Falle die schon in vivo diagnostizierte Myokarditis als einzige Ursache und glauben, daß genaue, auch histologische Untersuchung des Myokards öfter das gleiche Resultat ergeben werde. Münchheimer (Wiesbaden).

Reiche, F. Bakteriologische Erfahrungen beim Erysipel. Unnas Dermatologische Studien (Unna-Festschrift Bd. I). Bd. XX. pag. 506.

Reiche hat bei 83 Fällen von Erysipel 90 mal Blutkulturen angelegt. Nur dreimal war ein positiver Ausfall, zweimal gelang es, Streptokokken zu isolieren, einmal den Fränkelschen Diplococcus lanceolatus. 
Bei den beiden ersten Fällen bestand eine akute bämorrhagische Nephritis. Es ist demnach das reine umkomplizierte Erysipel eine in der Regel ohne Bakteriàmie verlaufende Erkrankung. Reiche ist der Ansicht, dab bei schweren Fällen von Erysipel vereinzelte Bakterien in den Blutstrom gelangen, daB aber ihre Zahl zu gering sei, um sich in wenigen com Blut demonstrieren zu lassen, und zweitens, daß die Blutzellen und die lebenden Gefäßendothelien diesen Keimen und ihrer Vermehrung ungünstig gegenüberstehen. Erst wenn letztere Einflüsse kurz vor und nach dem Tode erlöschen, erfahren die Mikroorganismen eine Entwicklungsbegünstigung. Es scheinen hier ähnliche Verhältnisse zu bestehen wie bei der Lungenphthise (365 Blutentnahmen beim Lebenden ergaben nur 6 mal ein positives Ergebnis, während bei 146 Leichenuntersuchungen sich 64 mal das Blut infiziert erwies). Fritz Juliusberg (Posen.)

Choksy, Bahadur. Über die äußere Anwendung von Magnesiumsulfat bei der Behandlung des Frysipels.

Angeregt durch eine Arbeit Tuckers (Therapeutic Gazette. April 1907) hat C hoksy das Magnesiumsulfat in gesättigter, wässriger Lösung bei Erysipel und Zellgewebsentzündung angewendet und empfiehlt seinen Gebrauch, da es die Schmerzen und die Schwellung beseitigt.

Fritz J uliusberg (Posen).

Haas, W. und Delbanco, E. Analdiphtherie. Unnas Dermatologische Studien (Tnna-Festschrift Bd, II). Bd. XXI. pag. 630.

Haas und Delbanco berichten ausführlich über einen Fall von Analdiphtherie, über den sich schon eine Mitteilung im Hamburger ärztl. Verein (Münchner med. Woch. 1909. Nr. 36) von De]banco findet. Es wird in der Arbeit aufs sorgfältigste die Literatur über diese und andere seltenere Lokalisationen der Diphtherie berücksichtigt und schließlich die Frage aufgeworfen, ob die Fäzes eine Anal- resp. Hautdiphtherie hervorrufen können. Diese Frage ist bes. auf Grund der Arbeiten von Na uwercks, Schödels und anderer za bejahen.

Fritz Juliusberg (Posen).

Müller, M., Gaehtgeus, W. und Acki, K. Vergl ei ch en de Untersuchungen zur Auswertung der diagnostischen Methodeu bei Rotz. (Ophthalmo-, Kutimalleinreaktion, Agglutination, Präzipitation, Komplementbindung, Opsonischer Index). Instit. für Hyg. u. Bakteriol. Straßburg. Zeitschrift f. Immunitätsf. Bd. VIII. H. 5 u. 6 . p. 626.

Keine diagnostische Methode vermag mit völliger Sicherheit das Vorliegen einer Rotz-Infektion in allen Stadien anzugeben. Als die beste und sicherste Methode zur Ermittelung klinisch nicht erkennbarer Rotzinfektionen ist die Malleinisation der Conjunctiva und der Haut, kombiniert mit dem Komplementbindungsverfahren anzusehen.

Da die serologische Blutuntersuclung durch die lokale Verwendung des Malleins keine Beeinträchtigung hinsichtlich ihrer diagnostischen Sicherheit erleidet, so ist die diagnostische Verwendung des Malleins und der Blutuntersuchung bei der praktischen Senchenermittlung aus dem 
Grunde angezeigt, weil die Malleinisation das einzige Verfahren bildet, das sich in der Seuchenbekämpfung unabhängig von einer Untersuchungsanstalt durchführen läßt.

Die diagnostische Sicherheit des Komplementbindungsverfahrens beginnt bei natürlicher Infektion im Verlaufe der zweiten Krankheitsworhe.

Die lokalen Malleinreaktionen vermögen das Vorliegen einer rotzigen Infektion bereits in der ersten Krankheitswoche anzugeben.

Die Agglutination und Präzipitation vermögen einen Teil der mit Rotz infizierten Tiere zu ermitteln; der negative Befund mit beiden Methoden bietet jedoch keine sichere Gewahr hinsichtlich der Senchenfreiheit der Tiere. Der negative Befund der Agglutination und Präzipitation ist daher nur dann als sicher zutreffend zu erachten, falls der Befund in Übereinstimmung steh $\downarrow$ mit einer negativen Malleinreaktion und Komplementbindung.

Der opsonische Index bietet für die veterinärpolizeiliche Rotzdiagnose keine binreichende Sicherheit.

M. Stern (Breslau).

Pinzani, Gino. Beitrag zum Studium der Innengranulationen des Milzbrandbazillus. Zentralbl. f. Bakt. Bd. LVII. H. 2. Dezember 1910 .

Die Arbeit befaßt sich mit einer höchst einfachen Färbemethode der Innengranulationen, deren Bedeutung noch nicht geklärt ist. Die Methode basiert darauf, daß sich bei der Färbung mit der Gramschen Methode die Körnchen intensiver färben als der übrige Bakterienkörper und der Einwirkung der Entfärbungsmittel länger widerstehen. Es wird die Gram-Färbung mittels enorm verdünnter Lösungen vorgenommen. Bezüglich der Details sei auf das Original verwiesen. Die Bazillen erscheinen dabei gelbbläulich gefärbt, die Sporen lebhaft rot und die Innenkörnchen intensiv violettbraun. Alfred Kraus (Prag).

\section{Tuberkulose.}

Urban, Otto. Dermatitis nodularis necroticans tuberculosa. Ikonographia dermatologica. Fasc. V. Tab. XLI.

Ein 15 Monate altes, in der Entwicklung zurückgebliebenes, rhachitisches Kind zeigte an der Haut des ganzen Körpers, besonders am Rumpfe, stecknadelkopfgroße, blaßbraun rosafarbige, derbe, leicht erhabene, z. T. lichenoide, schwach glänzende Effloreszenzen; viele davon sind von einer Schuppe bedeckt, nach deren Abstoßung eine zentrale Delle zurückbleibt. Beide Glutäalgegenden und Rückseiten der Oberschenkel tragen zahJreiche, derb infiltrierte, papulöse, mehr oder minder erhabene Effloreszenzen von hellroter bis bläulichroter Farbe, die keine Neigung zur Konfluenz zeigen und im Zentrum teils eine eingesunkene, flache Narbe, teils einen Substanzverlust, teils eine Schuppe aufweisen. 
Dauernde Temperatursteigerung. Die Hautaffektion des Rumpfes wurde als Lichen scrophulosorum, jene an den Glutäen beschriebene als Folliklis aufgefaßt, doch fielen die Tuberkulinreaktionen negativ aus. Die mikroskopische Untersuchung bestätigte die Diagnose; sie ergab ein scharf begrenztes Fundzelleninfiltrat mit einem zentralen Herde von tuberkelartigem Aufbau. Nach 7 Wochen erfolgte der Exitus an Meningitis tuberculosa und Miliartuberkulose. Wilhelm Balban (Wien).

Heuser, K. Ein Fall von Tuberculosis verracrosa cutis und tuberkulöser Lymphangitis, hervorgerufendurch Rindertuberkelbazillen. Dtsch. med. Woch. Nr. 6. 1911.

Heuser beobachtete das seltene Vorkommnis einer Hauttuberkulosis infolge einer Zeigefingerverletzung beim Schlachten tuberkulösen Viehs. Der Fingerwunde war eine Bläscheneruptıon und später eine über den Arm bis zur Achselhöhle fortschreitende Knotenbildung gefolgt. Wie klinisch und anamnestisch zu erwarten war, wurde bakteriologisch eine lymphatische Erkrankung des Armes durch Rindertuberkelbazillen festgestellt. Die Behandlung bestand in energischer Entfernung der größeren Paquelinisierung kleinerer Knoten, flacher Abtragung und Ätzverschorfung papillärer Wucherungen. Anzeichen von Lungentuberkulose lagen nicht vor, doch war die Pirquetsche Reaktion mit Altuberkulin und Perlsuchttuberkulin noch positiv, als sich der Patient der Behandlung entzog. Max Joseph (Berlin).

Ehrhardt, O. Primäre Tuberkulose der Mundschleimhaut und des Unterkiefers nach Zahnextraktion. Dtsche. med. Woch. Nr. 3. 1911.

Fh rhard t berichtet über das seltene Vorkommnis einer primären Mundschleimhauttuberkulose bei einem durchaus gesunden, aus unbelasteter Familie stammenden, 9jährigen Mädchen. Demselben war ein Prämolarzahn wegen Karies extrahiert worden, die Wunde heilte nicht zu, trotz Gebrauch desinfizierender Mundwässer trat eine Verdickung des Alveolarfortsatzes entsprechend der Extraktionswunde ein und die benachbarten Jrüsen vergrößerten sich. Die nähere Untersuchung ergab eine primäre Tuberkulose des Alveolarfortsatzes und der Mundschleimhaut mit sekundärer Erkrankung der regionären Lymphdrüsen. Das Bild des Schleimhautlupus war unverkennbar. Durch einen energischen chirurgischen Eingriff, Ausräumung der affizierten Drüsen in Narkose, Exzision der erkrankten Schleimhaut, Extraktion des 2. Prämolaris, Resektion des Alveolarfortsatzes mit der Hohlmeißelzange bis in den Unterkieferast, gelang es völlige Heilung zu erzielen. Max Joseph (Berlin).

Török, Ludwig. Klinische Beobachtungen über die embolische Hauttaberkulose. Unnas Dermatologische Studien (UnnaFestschrift, Bd. I). Bd. XX. p. 643.

Török berichtet zunächst über einige Fälle von embolischem Lupus vulgaris, die sich teils an Masern, teils an Scharlach angeschlossen hatten. Weiter kommt er auf den Lupus miliaris und das akneiforme Tuberkulid zu sprechen, ferner auf das embolische Skrophuloderma, wo er über drei 
Fälle berichten kann. Es folgen 10 Fälle von papulo-nekrotischen Tuberkuliden und 2 Fälle von Erythema indurativum. Török schließt aus seinen Beobachtungen, daß alle die genannten Formen durch die unmittelbare Einwirkung des Tuberkelbazillus auf das Hautgewebe zustande kommen. Man kann ferner aus dem gleichzeitigen Auftreten der verschiedenen großen, in verschiedenen Schichten der Haut gelagerten Herde von verschiedener Intensität den Schluß ziehen, daß die T'uberkelbazillen, durch welche diese Herde erzeugt wurden, von gleicher Qualität und Virulenz sind. „Man hat die Unterschiede in der Intensität des Krankheitsprozesses, im Grade der Nekrose, im Heiltriebe auch auf die Weise zu erklären versucht, daß man annahm, daß Differenzen in der Virulenz der Tuberkelbazillen beständen, ja man nahm sogar an, daß die milder verlaufenden Fälle vielleicht von Tuberbazillenleichen erzeugt werden." Nun hat Török sehr interessante verschiedenartige Kombinationen in den oben kurz angedeuteten Fällen beobachten können und er ist der Meinung, daß man die Ursache der Unterschiede nicht in solchen Virulenzverschiedenheiten der Bazillen suchen dürfe, sondern daß vor allem die Lokalisation des Embolus für die Art des entstehenden Herdes von Bedeutung ist. Soviel über die Arbeit, die ein außerordentlich reichhaltiges wertvolles kasuistisches Material zur Kenntnis der Tuberkulide und embolischen Hauttuberkulosen enthält. Fritz Juliusberg (Posen).

Nobl, G. Zur Kenntnis des multiplen, benignen Miliarlupoid Boeck. Unnas Dermatologische Studien (Unna, Festschrift, Bd. I). Bd. XX. p. 348.

Nobl berichtet über eine 25jährige Patientin, die er schon einmal in der Wiener Dermatologischen Gesellschaft (Wiener klin. Woch., 1909, Nr. 38) vorgestellt hat. Die Affektion war in diesem Falle mit seltener Akuität aufgetreten. Das Höhestadium war in vier Monaten erreicht. Es bestand die symmetrisch aufgetretene Affektion aus nadel- bis hanfkorngroßen, gelbbraunen, wenig erhabenen Flecken, die besonders auf der Stirn und den Wangen saßen und mächtigen, aus der Tiefe aufsteigenden, scharf abgegrenzten, dunkelbraunroten Infiltraten an den Augenlidern, den Wangen und dem Kinn. Es handelt sich um eine Kombination der kleinknotigen und der tief infiltrierenden Form des Miliarlupoid. Auch das histologische Bild entsprach dem bekannten, nur fand sich abweichend von den Angaben Boecks eine ziemlich reichliche, perialveoläre Ansammlung von entzündlichen Infiltrationszellen, die teils in Form breiterer Zonen die Lymphoidzellherde umrahmten, teils längs der Gefäße saßen. Diese Befunde sind erklärlich durch das frühe Stadium, in dem der ProzeB zur Untersuchung kam. Die herangezogenen Hilfsmittel der Tuberkulosereaktion ergaben ein negatives Resultat.

$$
\text { Fritz Juliusberg (Posen). }
$$

Bogoljepow. Ein Fall von gutartigem Sarkoid, das besser als benignes Miliarlupoid Boecks bezeichnet wird, lokalisiert ausschließlich am Handrücken und Dorsum der 
Finger in Form eines kreisförmigen Exanthems. Journal russe de mal. cut. 1910. Nr. 6. p. 301.

Das Resümee der Arbeit lautet: Der mitgeteilte Fall (39jährige Hausfrau) schließt sich vom klinischen Standpunkte am ebesten den Fällen von Brocq, Dubreuilh und Galloway an, unterscheidet sich aber von ibnen und von den Fällen von Fox, Rosch, Gregersen und Galewsky durch die bedeutende Ausdehnung auf beiden Handrücken, oder besser gesagt durch seine fast ausschließliche Lokalisation an diesen Stellen.

Histologisch wird er durch die Anwesenheit von Riesenzellen und Veränderungen (Schwund) im elastischen Gewebe an Stellen der stärksten Dichte des Infiltrats. Von derartigen Befunden wird von den Autoren, welche diese Varietät der Sarkoide Boecks beschreiben, keine Erwähnung getan.

Diese Beobachtung (Riesenzellen im Gewebe) führt zur Einreihung der Erkrankung unter den Begriff des benignen Miliarlupoid Boecks.

Alle Beobachtungen obgenannter Autoren, die diese Varietät der Sarkoide unter verschiedenen Namen beschreiben, müssen als gutartige Sarkoide oder besser als gutartige Miliarlupoide Boecks qualifiziert werden,

Die zutreffende Bezeichnung "gutartige Sarkoide", die vom histologischen und ätiologischen Standpunkte nicht entspricht, muB fallen gelassen werden. Zutreffender nennt man die Affektion: „benignes Miliarlupoid Boecks".

Dasselbe, besonders in Kreisform angeordnet, hat, wie die Beobachtungen von Brocq, Golloway und insbesondere von $R a \operatorname{ch}$ und Gregersen lehren, Beziehungen zur Tuberkulose. Sie repräsentiert eine abgeschwächte Hauttuberkulose oder ein Tuberkulid.

\section{Richard Fis chel (Bad Hall).}

Bolgolepow. Zur Frage des Lupus pernio (Besnier). Journal russe de mal. cut. 1910. H. 5. p. 237.

Bei dem 48jährigen Bauer begann das Leiden vor $2 \frac{1}{2}$ Jahren und breitete sich schmetterlingsförmig über die rechte Wange, Nasenrücken und zum kleinen Teile auf der linken Wange aus.

Histologisch fanden sich tuberkelartige Bildungen, die sich vom umgebenden Gewebe scharf abgrenzten und die, was besonders bemerkenswert erscheint, vaskularisiert waren.

Die Calmettsche Konjunktivalreaktion war negativ.

Der Lupus pernio stellt eine wahre Tuberkulose der Haut dar. unerläßlich.

Um die Frage der $\ddot{A}$ tiologie zu entscheiden, ist der Tierversuch

Der Lupus pernio hat eine innige Beziehung znm Erythema pernio und auf Grund des histologischen Befundes zum Erythema induratum Bazin.

Richard Fischel (Bad Hall).

Strandberg, O. Die Behandlung des Lupus cavi nasi mittelst Jodnatrium und Wasserstoffsuperoxyd nach der 
Methode von Dr. S. A. Pfannenstiel. Berlin. klin. Wochenschrift. 1910. Nr. 4. p. 166.

Der Verfasser ging von dem Gedanken aus, im kranken Gewebe selbst einen bakteriziden Körper darzustellen und so die Mikroben zu vernichten. Er gab daher seinen Patienten $3 \mathrm{~g}$ Jodnatrium pro die und ließ in die Nasenhöhle Tampons mit Wasserstoffsuperoxyd einfübren. Es wird hiedurch in der Schleimhaut $\mathrm{JNa}$ umgebildet und wieder in freies Jod von dem zugeführten Sauerstoffsuperoxyd abgespalten. Der Verfasser hat diese Methode an einer Reihe von Patienten angewendet und berichtet über günstige Erfolge. Hoobne (Frankfurt a. M.).

Ehrmann, S. Was ist Chilblain-Lupus von Hutchinson und was Lupus pernio von Besnier-Tenesson? Unnas Dermatologische Studien (Unna, Festschrift, Bd. II). Bd. XXI. p. 574.

Ehrmann kommt in seinen Ausführungen über die in der Überschrift angegebenen Krankheitsbilder zu folgenden Schlüssen: Der Lupus pernio von Besnier and Tenesson stellt eine knotige, scharf umschriebene, alveolär gebaute, aus Epitheloiden und spärlichen Riesenzellen bestehende tumorartige Erkrankungsform der Haut dar, während der Cbilblain-Lupus eine wesentlich andere, diffuse, der Epitheloiden und Riesenzellen völlig entbehrende, mit Gefäßveränderungen einhergehende Erkrankung bildet, die mit dem Lupus vulgaris nicht die entfernteste Ähnlichkeit hat, eher dem Lupus erythematosus nahekommt, höchstwahrscheinlich die Übergangsform $\mathrm{zwischen}$ akneiformen Tuberkuliden und Lupus erythematodes bildet, wie es bis jetzt scheint, immer mit Tuberkulose mit typischem akneiformen Tuberkulid und Lupus erythematodes zusammen vorkommt, wäbrend bei Lupus peruio von Besnier die Zusammensetzung mit Tuberkulose bisher noch nicht festgestellt worden ist. Fritz Juliu sberg (Posen).

Scaduto. Beitrag zur Pathogenese, Prophylaxe und Behandlung des Lupus vulgaris. Auszug aus „La Tubercolozi“. $\mathrm{Scaduto}$ tritt für die $\mathrm{Philippsonsche} \mathrm{Anschaung} \mathrm{ein,} \mathrm{wonach}$ der Lupus vulgaris in den meisten Fällen keine primäre, sondern eine anderen tuberkulösen Erkrankungen folgende Affektion darstellt. Bei genauer Untersuchung findet man oft bei den an Lupus leidenden Patienten tuberkulöse Adenitiden, Entzündungen der Mund- oder Nasenschleimhaut auf tuberkulöser Basis, tuberkulöse Arthrosynovitis oder Osteoperiostitis. Eine von diesen Erkrankungen ist gewöhnlich dem Auftreten des Lupus vorausgegangen. Besonders bei Kindern muß deshaib auf alle diese Affektionen geachtet und die Therapie dagegen gerichtet werden. Äußerst wirksam ist bei den tuberkulösen Erkrankungen des Drüsen- und Knochensystems die Applikation der Röntgenstrahlen. Es hat in der Mehrzahl der Fälle nicht viel Wert, den Lupus als solchen zu behandeln - von den zahlreichen Methoden kann jede einzelne nur bei dem primären Lupus von Nutzen sein - sondern die therapeutischen Maßnahmen müssen auf das tiefer liegende Übel hinzielen, von dem der Lupus abbängt. Nur die Beseitigung der primären tuberkulösen Affektion kann dauernde Heilung 
des Lupus bringen; wird der Lupus doreh lokale Mittel geteilt, ohne daß etwas gegen die primäre Krankheit getan wird, so sind Rezidive des Lupus die Folge.

J. Ullmann (Rom).

Philippson, L. Über die Tuberkulinreaktionen bei Lupus. Unnas Dermatologische Studien (Unna-Festschrift, Bd. I). Bd. XX. p. 184.

Philippson hat die Angaben von Wolff-Eisner (in "Frühdiagnose und Tuberkuloseimmunität") über die Lokalreaktionen beim Lupus vulgaris einer Nachprüfung unterzogen. Die Untersuchungen Wolff-Eisners hatten ergeben, daß beim Lupus der Haut die Konjunktivalprobe meist negativ ist. Dieser Autor ist der Ansicht, daß der Lupus meist durch eine äußere Infektion der Haut entstünde und daß von einem solchen tuberkulösen Herde keine Stoffwechselprodukte in die Haut gelangen. Philippson weist demgegenüber darauf hin, dab die Lupösen meist vorher an anderen tuberkulösen Affektionen gelitten haben. Er verwendete für das Auge eine 1\% ige, für die Haut eine $25 \%$ ige Tuberkulinlösung, die Probe wurde in der Weise ausgeführt, dab mit einer spitz ausgezogenen Glaskapillare, in die etwas Flüssigkeit gesogen war, ein oberflächlicher Einstich gemacht wurde. Es wurden an 39 Fällen von Lupus 24mal die Konjuntival- und 38mal die Kutanreaktion gemacht. Erstere war $17 \mathrm{mal}$ positiv und $7 \mathrm{mal}$ negativ, die Kutanreaktion war $32 \mathrm{mal}$ positiv und 6 mal negativ. Bei 5 Fällen von positiver Konjunktivalreaktion bestand außer dem Lupus keine andere tuberkulöse Affektion, was dafür zu sprechen scheint, daß der Lupus für sich allein auch positive Reaktion geben kann. Aus den Reaktionsprüfungen geht für den Autor hervor, daß man von einer Reaktion des Lupus schlechtweg überhaupt nicht sprechen dürfe, denn die Kranken leiden zumeist an anderweitigen tuberkulösen Affektionen oder haben solche früher durchgemacht. Auch bei reinen Lupusfällen (ohne anderweitige bestehende oder vorausgegangene Tuberkulose) bestand keine Konstanz der Reaktionen. Was die Bedeutung der Reaktionen für das trühzeitige Erkennen des Lupus betrifft, so meint Philippson: Die schweren Fälle sind nicht die, welche in kleinen Herden auftreten und stationär bleiben (grade die Fälle, für die Wolff-Eisner die Tuberkulinreaktion empfiehlt), sondern die, welohe die Weiterentwicklnng anderweitiger tuberkulöser Prozesse in die Haut darstellen. Bei diesen aber hängt der therapeutische Erfolg nicht vom frühen Erkennen der ersten Herde in der Haut $a b$, sondern von der frühzeitigen Behandlung der unter der Haut liegenden Mutterherde des Lupus.

Fritz Juliusberg (Posen).

Walker, Norman. Über die Behandlung des Lupuskarzinoms. Unnas Dermatologische Studien (Unna-Festschrift, Bd. II). Bd. XXI. p. 403.

Walker beschreibt in seiner Arbeit eine große Anzahl von Fällen von Lupuskarzinom und bildet sie ab. Er war früher für Entfernung des Kranken mit dem Messer, aber die große Mortalität unter den Fällen veranlaßte ihn diese Methode zu verlassen. Er zieht es jetzt vor, mit dem 
scharfen Löffel alles Kranke zu entfernen, wobei die Blutung mit Adrenalin gestillt wird. Es folgen dann Verätzungen mit starken Kaustizis, mit Chromsäure oder arseniger Säure. Ist es nicht möglich, die ganze Oberfläche auszukratzen, so ist die arsenige Säure vorzuziehen. Letztere ist allerdings außerordentlich schmerzhaft, auch die Chromsäure ist bei der Applikation sehr schmerzhaft, aber die Schmerzhaftigkeit geht vorüber. Fritz Juliusberg (Posen).

Nagelschmidt, Franz. Behandlung des Lupus mit besonderer Berücksichtigung der diesjährigen internationalen Lupuskonferenz. Zeitschrift für ärztl. Fortbildung. 1910. Bd. VII. p. 716 u. 751 .

Nagelschmidt stellt in einer kritischen Zusammenfassung über den augenblicklichen Stand der Lupusfrage in bezug auf die Therapie folgende Leitsätze auf. 1. In allen Fällen ist eine roborierende Allgemein behandlung einzuleiten und jede Infektionsmöglichkeit zu beseitigen. 2. Alle Fälle sind sorgfältig auf Schleimhautkomplikationen zu untersuchen und deren Behandlung muß sofort mit Diathermie in Angriff genommen werden (Lokalanästhesie). 3. Kleine Herde im Gesicht oder bei jungen Mädchen am Halse sind mit Pyrogallus oder Finsen zu behandeln. 4. An verdeckten Körperstellen oder bei Resistenz gegen diese Methoden ist die Diathermie indiziert. 5. Sehr große Fälle können mit Pyrogallus vorbehandelt werden; indessen ist ohne weiteres die Diathermie auch dort anwendbar. Für die Diathermie gibt es keine wegen ihrer Ausdehnung unzugängliche oder aussichtslose Fälle. 6. Das chirurgisch-plastische Verfahren ist lediglich als Nachbehandlung in geheiltem Gewebe anwendbar. 7. Vor jedem sonstigen blutigen Eingriff ist dringend zu warnen. 8. Die Tuberkulinbehandlung ist bei allen für Tuberkuloseinfektion disponierten Fällen, aber erst nach Beseitigung der lokalen Herde (bei Anwendung der Diathermie), anzuraten. Bei der Finsen- und Salbenbehandlung ist die Anwendung sofort indiziert. 9. Röntgen- und Radiumbestrahlungen sind zu vermeiden; desgleichen alle Verfahren, welche nur zu Besserungen (kosmetischen Heilungen) führen. V. Lion (Mannheim).

Senator, Max. Die Behandlung des Schleimhautlupus. Dtsch. med. Woch, Nr. 5. 1911.

Senat or tritt lebhaft für die chirurgischen Behandlungsmethoden des Schleimhautlupus ein, die zwar nicht stets eine wirkliche Heilung, aber doch gute Erfolge erzielen, ohne jemals Schädlichkeiten zu bedingen. Häufiger als eine vollkommene ist eine "soziale" Heilung der Erkrankung zu erreichen, denn die Rezidive erscheinen allmählich seltener und leichter. Es ist aber notwendig, die Schleimhaut ebenso sorgfältig wie die Haut eines Lupuskranken zu kontrollieren und in jerlem Falle das geübte Auge eines Rhino-Laryngologen zu Hilfe zu nehmen. Die Erkennung der oft ganz latenten Anfangsstadien bietet die beste Gewähr für eine aussichtsvolle Behandlung.

Max Joseph (Berlin).

Urban, G. Zur radikalen Behandlung des Lupus. Unnas Dermatologische Studien (Unna-Festschrift, Bd. II). Bd. XXI. p. 122. 
U r ban tritt in dieser Arbeit, wie in seinen früheren, für die radikale Behandlung des Lupus mit Exzision und Naht oder plastischer Deckung des Defekts ein. Er ist umsomehr von der Richtigkeit seines Vorgehens überzeugt, als es keine Methode gibt, die überwiegende Mehrheit der Lupusfälle zu heilen. Besserungen erzielen viele chirurgische und chemische Behandluwgsarten, einschließlich der Lichtmethoden. Für den Chirurgen kommen zunächst die allgemeinen Gruudsätze der Behandlung der chirurgischen Tuberkulose überhaupt in Frage. Hier steht die radikale Behandlung, die Entfernung alles Krankhaften mit scharfen Instrumenten obenan. Gegen die Operation mit dem Messer stellen Kontraindikationen unregelmäßige Tiefenentwicklung, der Utbergang auf Schleimhäute und akut entzündliche Nebenerscheinungen dar. Wo sich chirurgisch nicht alles radikal entfernen läßt, ist die Behandlung mit dem Paquelinschen Thermokanter die zweckmäßigste. Fritz Juliusberg (Posen).

Much, Hans. Welche Erkenntnisse wurden duroh die Entdeckung der granulären Form des Tuberkulosevirus bisher gewonnen? Unnas Dermatologische Studien (Unna-Festschrift, Bd. II). Bd. XXI. p. 95.

Aus den Ausführungen $\mathrm{Much}$ s über die Bedeutung der Entdeckung der granulären Form des Tuberkulosevirus sei speziell das sich auf die Hautkrankheiten beziehende referiert: Über das Vorkommen der granulären Form wissen wir beim Lupus einiges durch die Arbeiten von We i $B$, Doutrelepont und Krüger. Letztere konnten den Tuberkelbazillus in jedem Falle von Lupus vulgaris nachweisen, am häufigsten in der Muchschen Form. Doutrelepont hat auch angeregt, speziell bei den Tuberkuliden auf diese Granula zu fahnden. Bezüglich der Tierimpfungen bemerkt Much: „1. Doutrelepont meint, das Versagen der Tierimpfung daranf zurückführen zu können, daß3 sie im verimpften Stück in zu geringer $Z a h l$ vorkommen. Ich glaube indessen kaum, daß dieser Grund alles erklärt. Denn die allergeringsto Zahl wirklich virulenter Erreger vermag ja noch eine Meerschweinchentuberkulose hervorzurufen. Und wenn man Erreger noch in einem Schnittpräparat nachweisen kann, dann ist man im allgemeinen auch sicher, mit einem größeren Stücke des Materials Erreger zu verimpfen." 2. Vielleicht habeu wir es bei den Tuberkuliden mit einer abgeschwächten Form des Tuberkulosevirus zu tun, die sich klinisch, wie im Tierexperimente, vom vulgären Bazillus unterscheidet. 3. Die Granula können bei den Tuberkuliden von den ursprünglichen Bazillen abstammen, aber abgestorben sein. 4. Es können auch die Granula bei den Tuberkuliden von einem dem Tuberkelbazillus wahe verwandten Bazillus stammen. Fritz Juliusberg (Posen).

Jancsó, Nikolaus und Elfer, Aladár. Vergleichende Untersuchungen mit den praktisch wichtigen, säurefesten Bazillen. Beiträge zur Klinik der Tuberkulose. Bd. XVIII. H. 2.

Verfasser untersuchten: 1. die Frage der Virulenz verschiedener humaner Tuberkelbazillen, 2. die Frage, ob die verschiedenen humanen Tuberkelbazillen mittelst Tierpassage innerhalb einer gewissen Zeit ver-

Arch. f. Dermat. u. Syph. Bd. CIX. 
ändert werden können? Wenn ja, ob sie wohl nach irgendeiner Richtung hin eine bedeutende Annäherung zu sonstigen, praktisch wichtigen, säurefesten Bazillen aufweisen?

Umfangreiche Arbeit, die zum Referate nicht geeignet ist.

$$
\text { Wilhelm Balban (Wien). }
$$

Wolff-Eisner, A. Tuberkuloseimmunität und Tuberkuloseimmunisierung in ihrer klinischen Bedeutung. Folia Serologica. Bd. VI. H 1. 1910.

Wolff-Eisner schließt aus seinen Versuchen, daß es möglich ist, durch geeignete Vorbehandlung gesunder Tiere typische Tuberkulinempfindlichkeit hervorzubringen. Tuberkuline und Gifte der Tuberkelbazillen unterscheiden sich nicht voneinander, sondern sind als identisch anzusehen. Es gelingt, ohne lebende Tuberkelbazillen das typische Bild der Tuberkulose nebst der typischen Giftempfindlichkeit experimentell hervorzurufen. Prinzipiell ist deshalb eine Immunisierung ohne lebende Tuberkelbazillen möglich. Bei der tuberkulösen Infektion gelangen Stoffe in den Kreislauf, welche an Aufschließbarkeit den zerriebenen Tuberkelbazillen näber stehen als dem Alttuberkulin, da es nicht mit zerriebenen Tuberkelbazillen, dagegen mit Alttuberkulin gelingt, eine typische Tuberkulinempfindlichkeit zu erzeugen. Durch die Versuche glaubt der Verfasser bewiesen zu haben, daß seine Anschaung von der Endotoxinnatur des Tuberkulins richtig sei. Meirowsky (Cöln).

\section{Lepra.}

Pollitzer, S. Die Geschichte der Lepra in den Vereinigten Staaten. New York Academy of Medicine. 1910. Dez. 20. Medical Record. 1911. Januar 28. p. 176.

Eine Quelle für die Lepra in den Vereinigten Staaten war, wie Pollitzer ausführt, die Einführung der Negersklaven von Afrika. Der erste Bericht über die Lepra in den Vereinigten Staaten findet sich in Bernard Romans: A concise natural history of East and West Florida. 1775. Zu dieser Zeit existierte die Krankheit in Louisiana. 1786 war die Anzahl der leprösen Bettler in New-Orleans so groß, daß ein Eingreifen notwendig war. Es wurde damals das erste Leprabaus in den Vereinigten Staaten errichtet. Dann folgte die Verbreitung der Lepra über andere Teile. 1902 berichtete der Marine Hospital Service über 278 Fälle von Lepra in den Vereinigten Staaten, von denen die Hälfte in Louisiana sich befand. 145 davon waren in Amerika geboren, wahrscheinlich finden sich in Louisiana gegen 500 Lepröse. Fritz Juliu sberg (Posen).

Feindel, E. Di e Lepra in Kol u mb ien. La presse m. 1911. Nr. 15. Die Annahme einer präkolumbischen Lepra in Amerika hält $F$. für irrig; durch die eingehenden Untersuchungen von Montoya y Florez 
scheint ihm die Einschleppung aus der alten Welt bewiesen, zuerst durch Spanier, speziell Andalusier, später durch Schwarze aus Guinea, vom Kongo etc. mittels des sehr bedeutenden Sklavenhandels nach Süd-Amerika. Die Lepra breitete sich in Neu-Granada, dem heutigen Kolumbien, so schnell aus, daß schon 1615 eine Leproserie bestand und 1772 die Zahl der Leprösen auf 500 geschätzt wurde; heute beträgt sie nach M on to ya $4304=$ ca. $1 \%$ der Gesamtbevölkerung. Am zahlreichsten findet man die Kranken in den hochgelegenen Distrikten, in denen Wassermangel, große Unsauberkeit und jäher Temperaturwechsel ein Zusammendrängen vieler Personen in engen schmutzigen Gelassen zur Folge hat; deshalb ist dort auch Krätze enorm verbreitet, die Kratzwunden scheinen oft Eingangspforten für die Hausenschen Bazillen zu sein. An der Ozeanküste und längs der Flußläufe, also in den Bezirken der Fischnahrung, sind wenig Lepröse. Leproserien bestehen genügend, aber ohne ausreichende Absperrung gegen den Zutritt Gesunder, in allen Hauptorten; 3000 Kranke fand Montoya in ihnen. Übertragungen wurden, z. B. in kleinen, bisher immunen Orten, nach Zuzug eines Kranken mehrfach konstatiert. Es scheint direkte Lepra-Familien zu geben; die in den aufbewahrten alten Listen angeführten Familiennamen kehren in den neueren Statistiken immer wieder. Therapeutisch hat sich Nastin ebensowenig wie audere Mittel bewährt; den besten Erfolg, 7-10\% Heilungen oder erhebliche Besserungen, sah man nach einem von $\mathrm{Juan}$ de Carrasquilla (aus Bogotà) hergestelltem Serum. Schon die besseren hygienischen Verhältnisse in den Leproserien wirken oft günstig und einzelne Infektionskrankheiten, wie Frysipel und Variola, scheinen die Leprabazillen zu paralysieren. Mehrfach wurde auch Heilungstendenz abgeschwächter Formen beobachtet, wenn sie kräftige Leute befielen, die bei guter Körperpflege und Hygiene reichlich genährt wurden. Roborierende B€handlung ist daher angezeigt. Felix Münchheimer (Wiesbaden).

Cohn, Georg. Die oberen Luftwege bei den Leprösen des Memeler Lepraheimes. Zeitschrift für Laryngol, u. Rhinologie. Bd. III. Heft 4.

In einer Reihe von Fällen manifestieren sich die Initialerscheinungen der Lepra tuberosa nicht auf der äußeren Haut, sondern auf der Schleimhaut der oberen Luftwege. Im Verlaufe der Lepra kommt es fact stets zu Veränderungen in allen Teilen derselben. In der Nase kommt es zu einer Rhinitis, die je nach dem Stadium sich durch Katarrh und Nasenbluten, später durch Knotenbildung, endlich durch konzentrische Narbenverengerung, narbige Schrumpfung oder Zerfall charakterisiert. Seltener als die Nase ist der Racben befallen, wo die gleichen klinischen Erscheinungen wie dort auftreten. Die schwersten und für den Kranken bedrohlichsten Veränderungen sind jedoch jene, die sich im Kehlkopfe entwickeln können.

Die mikroskopische Untersuchung ergibt fast stets das Vorhandensein des Hausenschen Bazillus im Sekrete. Wilhelm Balban (Wien). 
Lie, H. P. Lepra tuberosa in den Handflächen, den FuBsohlen und am behaarten Teil des Kopfes. Unnas dermatologische Studien (Unna, Festschrift, Bd. I). Bd. XX. p. 383.

Die Lokalisation der Lepra hat an den in der Überschrift angegebenen Lokalisationen früher als große Seltenbelt gegolten. Wie Lie angibt, hat $B j a r n h j e d i n s o n$ die Lepra plantaris in $48 \%$, die Lepra palmaris in $19 \%$, die Lepra der Pars capillata in $23 \%$ seiner Fälle gefunden.

Bei der Lepra tuberosa palmaris sind typische Knotenbildungen nicht häufig, da die beginnenden Infiltrate bald applaniert werden. Man findet deswegen diffuse Infiltrationen, denen man früher keine Anfmerksamkeit schenkte. Anfangs sind sie schlecht zu fühlen, man sieht nur eine Verfärbung der Haut. Am häufigsten scheint der Hypothenar der Sitz der Affektion zu sein. Die diffuse Infiltration wächst sehr langsam, kann aber so groß werden, daß die Haut gespannt und glänzend wírd. Es besteht wenig Neigung zur Ulzeration. Bei der Lepra tuberosa plantaris finden sich ähnliche Verhältnisse. Auch die Lepra tuberosa des behaarten Kopfes ist nicht zu selten. Die klinische Form der Affektion ist wechselnd. Eigentliche lepröse Knoten hat der Autor nicht gesehen, wohl aber große und dicke Infiltrate, ferner kleine Follikulitiden und Perifollikulitiden, am häufigsten in Verbindung mit Hyperkeratose.

$$
\text { Fritz Julius berg (Posen). }
$$

Fox, Howard. Die Symptomatologie der Lepra. New-York Academy of Med. 1910. Dez. 20. Medical Record. 1911. Januar 28. p. 177. Kurzer Bericht über die Symptomatologie der Lepra, ohne Neues zu bringen.

Fritz $J$ uliusberg (Posen).

Biehler, R. und Eliasberg, Julius. Komplementbindung bei Lepra mit leprösem Antigen. Deutsche med. Wochenschrift. Nr. 7. 1911.

Ein brauchbares Antigen für Lepra fanden Biehler und Elias berg in durch $1 / 10 \%$ Normal-Schwefelsäure neutralisiertem $2 \%$ Antiforminextrakt aus Lepromen. Dieser Extrakt bindet das Komplement nur bei Anwesenheit leprösen Serums und zwar stärker, wenn Lepra tuberosa, schwächer, wenn Nervenlepra vorliegt. Das Serum Tuberös-Lepröser bindet allein stärker und häufiger als das Serum von Lepra nervorum das Komplement. Nastin- oder Ol. Gynocardiae-Gebrauch beeinflussen die Reaktion nicht.

Max Jose p b (Berlin).

Eliasberg, Julius. Über das Fehlen freien Komplementes im Blute Lepröser. Deutsche med. Wochenschr. Nr. 7. 1911.

Die eingehenden Studien Eliasbergs ergaben, daß im Serum Lepröser kein freies Komplement, hingegen freie Ambozeptoren und Antigene nachzuweisen waren. Das Serum progressiver Paralytiker enthält kein Komplement, aber Ambozeptoren und wahrscheinlich auch Antigene, da diese sich in der Zerebrospinalflüssigkeit finden. Das Feblen des Komplements bei Anwesenheit von Ambozeptor und Antigen im Blute ist vielleicht die Ursache der Unheilbarkeit von Lepra und progressiver Paralyse. Neben diesen Befunden ergab die Prüfung normalen 
Serums die interessante Tatsache, daß bei dem physiologischen Vorgange der Verdauung Komplement verbraucht wurde.

Max Joseph (Berlin).

Campana, R. Über die Kultur des Leprabazillus und die Übertragung der Lepra auf Tiere. Zeitschrift für Hygiene und Infektionskrankheiten. 1910. Bd. LXVII. p. 361.

Kulturen von Bazillen, welche die Merkmale der Leprabazillen zeigen, sind nach des Verf. Untersuchungen nur auf festen, neutralen anaeroben Nährboden zu erhalten. Die Kulturen lassen sich, wenn rechtzeitig überimpft, unbegrenzt fortptlanzen. Die Lepra ist auf Tiere nicht übertragbar. An der Impfstelle können die Leprabazillon lange Zeit liegen bleiben und den Anschein einer gelungenen Infektion erwecken; aber diese lokale Erscheinung läßt sich nicht nur mit lebendem, sondern auch mit totem Material erzielen, beispielsweise mit leprösem, $10 \mathrm{Jahre}$ auf bewahrtem Gewebe, in dem die Leprabazillen wohl abgestorben waren. Nach längerem Gebrauch von Nastin ist eine lokale Reaktion beim Leprösen nicht zu verkennen.

V. Li on (Mannheim).

Unna, P. jun. Zur Mikrochemie des Leprabazillus. Unnas Dermatologische Studien (Unna-Festschrift, Bd. II). Bd. XXI. pag. 283.

U $n \mathbf{n}$ a jun. hat es sich in dieser Arbeit zur Aufgabe gestellt, über den chemischen Bau der Leprabazillen weitere Aufschlüsse zu gewinnen. Die Untersuchungen wurden ausgeführt an sehr fein verteiltem Lepramaterial, das er als „Leprahack“ (P. G. Unna: Histotechnik der leprösen Haut) bezeichnet. Die Herstellung wird ausführlich angegeben. Bisher unter. schied man an den Lepraorganismen die durch Säuren darstellbare Bazillenform von der durch Jod darstellbaren Kokkothrixform. Diese letztere muß man unterscheiden von einer auf verschiedene Weise darstellbaren Form der extrahierten Bazillen, die der Autor als "Gliederform" bezeichnet. Diese Befunde sind nicht identisch mit den jodophilen Körnern von Lutz. Die Fuchsin + Gentianajodmethode läßt beide zur Darstellung bringen, die Glieder rot, die Körner blau. Weiter beschreibt der Autor das Verhalten des Hacks gegen die verschiedenen Extraktionsflüssigkeiten und das Verhalten der Bazillen bei verschiedenen Färbemethoden. Die Resultate sind in Tabellen dargestellt. Die tatsachenreichen Ausführungen müssen im Original studiert werden. Fritz Juliusberg (Posen).

Boeck, C. Über das Herstammen und das weitere Schicksal der mit den Faeces entleerten Leprabazillen. Unnas Dermatologische Studien (Unna-Festschrift, Bd. I). Bd. XX. pag. 436 .

Boeck kommt in seinen Ausführungen zu folgenden Schlüssen: 1. Hauptsächlich sind es die tuberösen Fälle von Lepra, die mit Ulzerationen in Mund, Schlund und Kehlkopf verbunden sind, bei welchen Leprabazillen in den Faeces vorkommen. 2. Die Bazillen stammen in solchen Fällen hauptsächlich, vielleicht ausschließlich, von den Ulzerationen der genannten Organe. 3. Kaum auf irgend einem anderen Wege, 
als eben mit den Stühlen, werden in solchen Fällen täglich so große Mengen Leprabazillen ausgeschieden. 4. Die Bazillen können auch sehr lange Zeit (mehr als ein halbes Jahr) nach der Entleerung der Faeces, ebenso zahlreich wie trüher, in denselben nachgewiesen werden.

Fritz Juliusberg (Posen).

Duval, Charles. Über experimentelle Lsepra und Serum. therapie bei Lepra. New-York Academy of Medicine. 1910. Dec. 20. Medical Record. 1911. Januar 28. p. 177.

Duval hat den Leprabazillus bei acht Fällen von Lepra aus Hautknoten rein gezüchtet und hat Lepra auf Tanzmäuse übertragen können. Leider enthält der Vortrag keine genauen Angaben über Technik usw.

Fritz Julius berg (Posen).

\section{Parasitäre Erkrankungen.}

Plaut, H. C. Technisches und Theoretisches beim Nachweis der Hyphomyzeten in der Haut. Unnas Dermatologische Studien (Unua-Festschrift, Bd. II), Bd. XXI. p. 308.

Aus Plauts hochinteressanten Arbeit ist es im Rahmen eines kurzen Referates nur möglich, einiges praktisch besonders Wichtige mitzuteilen. Zum Nachweis von Pilzen in Schuppen und Haaren legt man die Epidermiselemente in $15 \%$ ige Kalilauge unter dem Deckglas ohne aufzukochen für 12 bis 20 Stunden. Bessere Resultate erzielt die Aufhellungsmethode mit heißer Ameisensäure (Annales de derm. 1892. p. 709) oder mit der Anwendung sehr starker heißer Pottaschelösung (Annales de dermat. 1907. p. 224) nach Sabouraud. Aber allen diesen Mitteln vorzuziehen ist das Antiformin. Man stellt eine 10- bis 25\% ige Antiforminlösung her und bringt das zu untersuchende Material hierin auf einen Objektträger, den man nach 2 Minuten mit einem Deckglas bedeckt. Konservieren lassen sich diese Präparate nach Auswaschen und Zusatz von etwas Glyzeringelatine. Das Antiformin darf nicht länger als 1/2 Stunde einwirken. Handelt es sich um Kulturen aus Haarstümpfen, so legt man eine Anzahl verdächtiger Stümpfe auf einen vorher sterilisierten Objektträger in eine feuchte Kammer und untersucht, nachdem sie drei bis sechs Tage bei Zimmertemperatur gestanden haben.

Weiter geht der Verfasser auf die Momente ein, die eine Pilzdiagnose bei den Mikrosporieformen ohne Zuhilfenahme spezifischer Nährböden gestatten. Erwachsene leiden fast nie an Pilzaffektionen des behaarten Kopfes, ausgenommen den Favus. Bei Kindern schneidet man die Haare kurz. Seine weiteren Ausführungen hat Plaut zum Teil in übersichtlichen Tabellen dargestellt. Vor allem interessant sind die Wachstumsschemata der verschiedenen Pilze. Der Leser sei eindringlichst auf die Originalarbeit verwiesen. Fritz Juliusberg (Posen). 
Beck, S. C. Über das Erythema mycoticum infantile Un n as Dermatologische Studien (Unn a-Festschrift, Bd. I), Bd. XX. p. 294.

Beck nimmt auf Grund klinischer und mikroskopischer Untersuchungen an, daß es außer den bekannten und gewöhnlichen Formen des Erythema glutaeale infantile oder Dermites infantiles von Jacquet eine ganz spezifische Erkrankung des Säuglingsalters gibt, welche von den oben genannten Dermatosen streng geschieden werden muB und mit dem Namen Erythema mycoticum infantile bezeichnet werden kann. Fr glaubt, daß die nicht recht charakteristischen Fälle, welche $J$ acquet als Dermites erythemato-squameuses bezeichnet hat und von denen er selber behauptete, dal3 sie noch nicht genügend durchstudiert sind, nichts weiter sind als Fälle von Erythema mycoticum infantile. Dieses Erythem kann von der Glutäalgegend ausgehend sich in jeder Richtung ausbreiten. Es hat nichts mit Störungen der Magen-Darmfunktion zu tun. Es wird durch einen Pilz verursacht, dessen Charaktere zwar noch nicht vollkommen aufgeklärt sind, der aber große Ähnlichkeit mit dem Soorpilz der Säuglingsmundschleimhaut hat und morphologisch auch dem Kü sterschen Pilz der Badetrichophytie nahe steht.

Fritz Julius berg (Posen).

Ibrahim, $J$. Über eine Soormykose der Haut im frühen Säuglingsalter. Archiv f. Kinderheilk. Bd. LV. p. 91.

I. hat bei mehreren Kindern der ersten Lebenswochen im eitrigen Inhalt von in der Umgebung des Genitales sitzenden Bläschen Soorpilze nachweisen können. Es handelt sich um eine unmittelbare Infektion der Haut mit dem Pilz und zwar höchstwahrscheinlich durch die Faezes, die Soor enthielten. Besondere pathognostische Zeichen des Krankheitsbildes lassen sich nicht angeben. Es ist stets diese Diagnose in Betracht zu ziehen, wenn es sich um Bläscheneruptionen bei einem Säugling der ersten Lebenswochen handelt, der an einer Soorerkrankung der Mundhöhle leidet. Die Soormykose der Haut ist wahrscheinlich kein seltenes Leiden und besonders dort anzutreffen, wo die 3 ätiologischen Faktoren: Soorinfektion, schlechte Pflege und Neigung zu intertriginösen bzw. ekzematösen Hauterkrankungen zusammentreffen. Wenn auch der Soorpilz mit einiger Wahrscheinlichkeit das eine- oder anderemal als Erreger des Hautleidens angesehen werden kann, so ist doch andererseits anzunehmen, daß es sich häufiger um eine sekundäre Infektion einer bereits geschädigten Haut handelt.

C. Leiner (Wien).

Heath, Douglas. Ein Fall von Favus. Midland Medical Society. 1910. Dez. 14. The Lancet. 1911. Januar 14. p. 103.

Heaths Fall von Favus vom Bauche eines 2jährigen Kindes ist dadurch bemerkenswert, daß es sich nach den Kulturen um das Achorion quinckeanum von Bodin handelte, eine seltene Varietät des Favus, die schnell in weißen flaumigen Kulturen wächst.

Fritz Juliusberg (Posen).

Schramek, M. Wien. (Klinik Riehl.) Über Mikrosporie Wiener klin. Wochenschr. 1910. Nr. 48. 
Schramek beobachtete anfänglich bei 3 Kindern das Krankheitsbild der Mikrosporie und konnte dann bei Nachforschung in den Schulen 5 weitere Fälle konstatieren und behandeln. Der Autor bespricht die klinische Diagnose, erwähnt die Schwierigkeit derselben im ersten Beginne der Erkrankung, weil daselbst die abgebrochenen Haare nur spärlich vorkommen und die typischen manschettenartigen Scheiden gänzlich fehlen. Absolute Sicherheit gewährt die mikroskopische Untersuchung der Haare und der kulturelle Befund. Therapeutisch kommt die vollständige Epilation durch Röntgenstrahlen und nachträgliches Aufpinseln von Jodtinktur in Betracht.

Viktor Bandler (Prag).

Sutton, Richard. Sporotrichose in Amerika. The Journal of the Americ. Med. Association 1910. Dez. 24. p. 2213.

Seitdem Sutton in derselben Zeitscbrift (Sept. 17) einen Fall von Sporotrichose mitgeteilt bat, wurden vier weitere Fälle in Amerika veröffentlicht, einer von Stellwagon (sein Lehrbuch 1910), je einer von Pusey, von Hyde und Davis und Zuraski (Journ. cutan. diseases). Eine traumatische Läsion der Hand, des Unterarmes oder Beines, die der gewöhnlichen chirurgischen Behandlung Widerstand entgegensetzt und begleitet ist von der Entwicklung einer oder mehrerer scharf umschrie. bener, schmerzloser Abszesse in der Haut oder Subkutis, die dem Gliede entlang laufen, sollte immer Verdacht auf Sporotrichose erregen, besonders wenn entzündliche typische Manifestationen einer Streptokokkenzellulitis tehlen, Es folgt die Krankengeschichte zweier neuen Fälle von Sporotrichosis und die Mitteilung eines Falles von ulzerierter gummöser Syphilis; der sehr ähnlich der Sporotrichosis aussah.

Fritz Juliusberg (Posen).

de Beurmann. Leishmaniosis ulcerosa cutis. Ein Fall von in Jericho akquirierter Orientbeule. Ikonographia dermat. Fasc. V. Tab. XXXVI.

Die Erkrankung des 68jähr. Patienten trat nach einer Pilgerfahrt ins heilige Land auf, wo die Pilger in Jericho sehr unter den Stichen von Mosquitos zu leiden hatten. Die Affektion entwickelte sich aus roten, elevierten, entzündeten, heftig juckenden Knötchen an beiden Beinen, die, zwölf an der Zahl, sich auch späterhin nicht vermehrten. Diese Knötchen, infolge des heftigen Juckens aufgekratzt, vergrößerten sich und exulzerierten. Bei der Untersuchung konnte man drei verschiedene Arten von Knoten, je nach dem Grade der Entwicklung, beobachten. Die kleinsten nehmen die ganze Dicke der Haut ein, welche violett verfärbt und leicht vorgewölbt ist; die gröBeren Kuoten sind an der Oberfläche erodiert, von einer dicken, unregelmäBigen, bräunlichen Kruste bedeckt, nach deren Ablösung eine papillomatöse, violettrote, leicht sezernierende, aber nicht eiternde Basis erscheint. Die grcßen Knoten endlich, zwei an der Zahl, mit einem Durchmesser von $3 \mathrm{~cm}$, zeigen eine violettrote Basis, die von großen, papillomatösen Wucherungen abwechselnd mit kleinen, becherförmigen Vertiefungen bedeckt ist; in letzteren spärliche Eitersekretion. Die Ränder sind unregelmäßig, gezackt und von einem violetten Hofe 
umgeben. Kein Ödem, keine Schwellung der Lymphgefäße und -Drüsen, kein Fieber.

Die Behandlung, der Patient s1ch aber entzog, hätte in der Applikation von pulverisiertem Kalium hypermanganicum uud, nach Entfernung des entstandenen Detritus, von Umschlägen mit Methylenblaulösung bestanden.

Die bakteriologische Untersuchnng ergab das Vorhandensein von Leishmania tropica. Die Übertragung durch Insektenstich, die in diesem Falle angenommen wird, ist auch sibon von anderen Beobachtern bestätigt worden. Wilhelm Balban (Wien).

\section{Sonstige Dermatosen.}

Fränkel, Eugen. Über metastatische Hautaffektionen bei bakteriellen Allgemeinerkrankungen. Unnas Dermatolog. Studien (Unna-Festschrift Bd. I), Bd. XX. p. 74.

Fränkel leitet seine Arbeit ein mit einer Erörterung der TyphusRoseola als Beispiel der Beteiligung der Haut an durch Bakterieninvasion in den Organismus veranlabten Allgemeinerkrankungen. N e u feld hat eine einfache Methode für die Kultur der Typhusbazillen aus Roseolenblut angegeben. Fränkel selbst konnte in den exzidierten Roseolen die in der Haut abgelagerten Typhusbazillen demonstrieren. Trotzdem ist noch mancher Punkt bezüglich der Typhusroseola ungeklärt, vor allem die eigenartige Lokalisation der Effloreszenzen. Als Beispiel, daß durch ungünstige Wachstumsbedingungen in der Haut es bei Infektionskrankheiten selten zu Hauterscheinungen kommt, wird Leichtensterns einziger Fall von Exanthem bei akuter Miliartuberkulose erwähnt.

Der erste Fall Fränkels betrifft einen Fall von Staphylokokkenmetastasen der Haut. Bei einem 7jährigen Mädchen fand sich neben akuter eitriger Osteomyelitis, Metastasen in den verschiedensten Organen ein Exanthem an den Extremitäte und am Rumpf, bestehend aus kleinen bläulichen, leicht prominenten Herden mit einem grauen Zentrum. Histologisch fand sich ein kleiner kugeliger Herd an der Grenze von Korium und Subkutis, mit Ausläufern ins Unterhautzellgewebe und ein zweiter miliarer Herd am Übergang der Pars papillaris in die Pars reticularis cutis. Histolog. handelte es sich um dichte Leukozytenansammlungen; im Zentrum der Herde fanden sich mit Staphylokokken prall gefüllte Arterienästchen. Außerdem fanden sich reichliche Mengen fein- und grobtropfigen Glykogens steils frei, teils in Leukozyten. Wie dieser Fall und ein entsprechender Unnas (Atlas zur Pathologie der Haut, Heft III) zeigen, kann die Haut auf eine hämatogene Infektion unter Umständen mit einem quaddelartigen, bisweilen einen hämorrhagischen Charakter an sich tragenden Exanthem antworten. 
Keineswegs dürfen alle derartigen Staphylokokkämien an der Hautdecke mit hämorrhagischen und pustulösen Effloreszenzen als Metastasen aufgefaßt werden, ein Teil derselben wird durch ektogene Infektion bedingt, so der "staphylogene Impetigo".

Der zweite Fall stellt eine Hauterkrankung bei einer Streptokokkämie dar. Es finden sich neben einer durch den Streptococcus viridis bedingten Herzklappenerkrankung bei der Sektion an der Streckseite beider Hände in großer Zahl äußerst dicht zusammenstehende, kaum mohnkorngroße hämorrhagische Effloreszenzen, von denen viele ein kaum stecknadelspitzengroßes gelbliches Zentrum erkennen ließen. Histologisch fand sich eine Quellung des kollagenen Gewebes, geschwollene fixe Bindegewebszellen und spärliche Leukozyten. Die kollagenen Fasern waren teilweise vernichtet, teilweise stark geschädigt; vereinzelte Kokken in Diploform, in einem der Herde in einem größeren Arterienästchen. Nach der Bestschen Methode fanden sich zwischen den gequollenen und z. T. nekrobiotischen Bindegewebsfasern, fein- und grobkörniges Glykogen, das in sehr beträchtlicher Menge auch in den Epithelien der benachbarten, in gesunden Hautbezirken liegenden Knäuldrüsen abgelagert ist. Fränkel schließt sich bzw: des Glykogens den Autoren an, die die Anwesenheit von Glykogen in den Knäuldrüsen immer mit pathologischen Vorgängen in der Haut selbst in Verbindung bringen. Übrigens beweist der nächste Fall, daß keineswegs regelmäßig bei mit Glykogenbildung einhergehenden, in der Haut lokalisierten Krankheitsprozessen auch ein Auftreten von Glykogen in den Knäuldrüsen vorhanden zu sein braucht. Unna hat einen ähnlichen Fall als "Phlyctaenosis streptogenes" beschrieben. Wichtige Bejträge zu fleckenartigen Hautblutungen bei septischen Erkrankungen finden sich bei Lenhartz (1903) "Über die septischen Erkrankungen". Beim dritten Fall handelte es sich um eine durch den Friedländer Bazillus veranlaßte, von einer ausgedehnten pneumonischen Erkrankung beider Lungen ausgegangene Blutinfektion, die unter anderem auch zu einer isolierten, klinisch als Furunkel gedeuteten, metastatischen Erkrankung der Haut geführt hatte. $\mathrm{DaB}$ es sich tatsächlich um eine Metastase gehandelt hat, ist durch den kulturell erbrachten Nachweis des aus dem Gewebssaft der erkrankten Hautpartie gezüchteten, mit dem im Blute angesiedelten identischen Bazillus einwandsfrei festgestellt. Mikroskopisch handelte es sich bei dem Hautherde um einen rein eitrigen Prozeß der Subkutis, einer zirkumskripten Phlegmone. Die massigsten Bakterienvegetationen fanden sich in der Tiefe der Subkutis. Der Friedländer-Bazillus umfaßt eine Reihe unterschiedbarer Arten. Im vorliegenden Falle handelte es sich um den Bacillus mucosus capsulatus, der nach F. dem $\mathrm{Abelschen} \mathrm{Ozaenbazillus} \mathrm{identisch} \mathrm{ist.} \mathrm{Der} \mathrm{Fall} \mathrm{erinnert}$ an einen Fall von Breinl „Über einen Fall von Pseudoleucaemia intestinalis mit durch Kapselbazillen bedingter Peritonitis“ (Prager med. Woch. Jahrg. 29).

Der vierte Fall betrifft ein Exanthem, welches durch den Bacillus pyocyaneus verursacht war. Bei den metastatischen, durch den Bac. 
pyoc. hervorgerufenen Herdaffektionen führt die eigenartige Ansiedlung des Bazillus innerhalb der Wände der feineren Arterien anch in der Haut zu den makroskopisch sichtbaren, den Charakter eines bämorrhagischfleckigen oder knötchenartigen, weiterhin hämorrhagisch-bullösen Exanthems darbietenden Efforeszenzen. Fritz Juliusberg (Posen).

Pernet, George. Ein ungewöhnlicher Fall von toxischer Dermatitis; mit Bemerkungen über symmetrische Eruptionen. The Brit. Med. Journ. 1910. 17. Dez. p. 1907.

Pernets Patientin hatte von einem schlechten Kaninchen gegessen. Sie bekam darauf ein symmetrisch verteiltes Exanthem, das in wiederholten Schüben auftrat. Pernet erinnert im Anschluß an die auffallende Symmetrie dieses Falles an andere symmetrisch auftretende Hauterkrankungen, speziell an den Lupus erythematosus.

Fritz Juliusberg (Posen).

Ruediger, E. Über ein durch Toxinresorption bedingtes Hauterythem bei Bronchiektasien. Archiv f. Kinderheilkunde. Bd. LV.

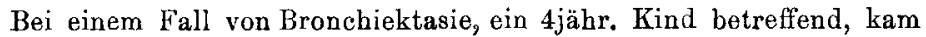
es gewöhnlich in den Morgenstunden zur Zeit des Angefülltseins der Bronchiektasie mit Eiter zum Auftreten eines bläulichroten, fleckigen Erythems im Gesichte, das im Laufe des Tages, nach Abhusten des Eiters wieder verschwand. Es dürfte sich hier um eine lokale Schädigung der Gefäbinnervation durch Toxine handeln.

C. Leiner.

lless, Otto. Ein Fall von "Hyperkeratosis" mit ausgedehnter Borkenbildung nach Anwendung eines „Einreibemittels". Dtsch. med. Woch. Nr. 4. 1911.

Gegen Arthritis deformans hatte die von $\mathrm{Hess}$ beobachtete $\mathrm{Pa}$ tientin ein "Volksheilmittel" in Gestalt einer schwärzlich-braunen; übelriechenden Flüssigkeit zum Einreiben gebraucht, in dem bei chemischer Untersuchung Asa foetida nachgewiesen wurde. Die Folge hiervon war eine eigenartige Hyperkeratosis: harte, rissige, braune Borken, unter denen bei Abhebung zum Teil normale Haut, zum Teil eine wie mit spitzen, weißen Wärzchen bedeckte, wenig blutende Unterlage erschien, die Nägel waren onychogryphotisch. Unter Bäderbehandlung heilte die Hautaffektion, die sich auch histologisch (Atrophie der Papillen, schroffer Übergang der Retezellen in das verdickte Stratum corueum) als Hyperkeratose darstellte. Max Joseph (Berlin).

v. Zumbusch, Leo. Die toxischen (Arznei-) Exantheme. Aus Jesioneks Praktische Ergebnisse anf dem Gebiete der Hant- und Geschlechtskrankheiten. Wiesbaden. Verlag von J. F. Bergmann. 1910.

So interessant das Kapitel der toxischen Exantheme ist, so schwierig ist eine zusammenfassende Darstellung dieses Gebietes, dessen Grenzen außerordentlich schwer zu ziehen und dessen Kasuistik überall verstreut und außerordentlich reichhaltig ist. v. $Z u m b u s c h$ hat versucht, im vorliegenden Kapitel einige Fragen zu beavtworten. Zunächst wirft er dic Frage auf, ob es möglich ist, gemeinsame chemische oder pharmako- 
logische Eigenschaften der Mittel festzustellen, die als Erreger von Hauterscheinungen bekannt sind. Diese Frage ist zu verneinen, auch ist es nur zum Teil möglich, Gruppen dieser Körper zusammenstellen, die gemeinsame Merkmale aufweisen. Auch die Frage, ob man aus irgendwelchen Merkmalen beim Menschen voraussagen kann, wie groß seine Disposition zu toxischen Exanthemen ist, ist entschieden zu verneinen. Es steht fest, daß in der Mehrzahl der Fälle an die toxisch wirkenden Mittel eine Gewöhnung nicht eintritt, vielmehr daß die Mittel zuerst ev. anstandslos vertragen, später erst Vergiftungserscheinungen hervorrufen. Er debattiert weiter das Kapitel der Anaphylaxie und schlieBt: „Die toxischen Erytheme können nicht in eine Reihe mit anderen Vergiftungserscheinungen gestellt werden, bei Intoxikationen, die schwere Allgemeinsymptome auslösen, fehlen sie meist." Das zweite Kapitel behandelt die klinischen Erscheinungen der toxischen Exantheme. Hier ist der Stoff nach den einzelnen Chemikalien geordnet und ermöglicht also leicht eine Orientierung.

$$
\text { Fritz Juliusberg (Posen). }
$$

Timel. Chronische Dermatitis hervorgerufen durch Einspritzungen von Hydrargyrum vivum. Journal russe de mal. cut. 1910. Nr. 5. p. 260.

Der 20jährige Patient, Jurist, hat sich infolge von Syphilophobie 135-140 g Hg. vivum selbst im Laufe eines Monats injiziert. Über den Injektionsstellen, der linken Hüfte, neben und unterhalb des Nabels, in beiden Leistengegenden, an der Innenfläche beider Oberschenkel und den Kniegelenken) etablierten sich entzündliche Hautveränderungen, die aus Knötchen, Knoten und länglichen Infiltraten von roter und zyanotischer Farbe bestanden.

Histologisch fand sich das Bild chron. Entzündung mit mächtiger Pigmentablagerung infolge von Kapillarzerreißung durch das schwere Metall. Kein Zeichen von Merkurialismus. Dazu 3 Tafeln.

Richard Fischel (Bad Hall).

Taylor, Alonzo Englebert. Ein wahrscheinlicher Fall von Anaphylaxie. The Journal of the American Medical Association. 1911. 11. Februar. p. 418.

Taylor berichtet folgenden eigenartigen Fall. Ein Arzt hat bei einem Fall von Beulenpest die Sektion ausgeführt. Zur Sicherheit injizierte er sich $30 \mathrm{ccm}$ Yersins Serum. Er bekam keine Infektion, auch nicht andere üble Folgen. Fünf Jahre später verletzte er sich auf der Jagd. Da die Wunden nicht gut aussahen, injizierte er sich $20 \mathrm{com}$ Antitetanusserum. Einige Stunden später Riesenurtikaria, Tachykardie, Diarrhoe, neuritische Erscheinungen. Der Autor bringt die Erscheinungen nach der Injektion des Tetanusserum mit der Injektion vor 5 Jahren in Zusammenhang und faßt den Vorgang als einen Fall von Anaphylaxie gegen Pferdeserum auf. Fritz Juliusberg (Posen).

Pryce, A. M. Über einen Fall von unmittelbar einsetzender Serumreaktion. The Lancet 1910. 17. Dezember. p. 1760. 
Ein diphtheriekrankes Kind bekam, wie Pryce berichtet, eine Einspritzung von Diphtherieantitoxin, subkutan in die Baucbgegend. 15 Minuten später erfolgte eine typische dicbtgedrängte Urtikaria über den ganzen Körper, die zwei Tage auf ihrer Höhe bestand und dann allmählich abklang. Am 7. Tage nach der Injektion entstand eine zweite urtikarielle Eruption. Fritz Juli us berg (Posen).

Balfour, Andrew. X-Körper im menschlichen Blute. The Lancet 1911. 4. Februar. p. 295.

Der Fall, von dem die Blutpräparate Balf ours herstammen, betrifft eine 18jähr. weiße Dame aus dem Sudan, die seit einiger Zeit an einer eigentümlichen Urtikaria leidet. Von Nachtanbruch an bis zum Morgen entstehen Quaddeln, die heftig jucken und brennen, sonst sind keine Krankheitssymptome vorhanden. Im Blute fanden sich Bildungen wie sie Horrocks und Howell (X bodies found in the blood of human beings and animals. Journal of the Royal Army Medical Corps. Vol. X. Nr. 4) beschrieben haben. Sie fanden sich nur in einem Präparat. Kulturversuche führten zu keinem Ergebnis. Fritz Juliusberg (Posen).

Fülleborn, Friedrich. Kasuistische Beiträge zur Pathologie der Südsee-Eingeborenen (Rhinopharyngitis mutilans und andere ulzeröse Prozesse). Unnas Dermatolog. Studien (Unna Festschrift Bd. II), Bd. XXI. p. 422.

Fülleborn berichtet neben der Darstellung einer Anzahl nicht mit Sicherheit diagnostizierter Krankheitsbilder über eine Reihe von Fällen einer Krankheit, die in der Südsee, Westindien und anderen 'Tropenländern als , Rhinopharyngitis mutilans" oder "Gangosa" beschrieben wurde. Über die Ätiologie sind die Meinungen noch zu keinem Abschlaß gekommen. Einige halten sie für tertiäre Syphilis, andere für Framboesie, andere für eine selbständige Krankheit. Die Fälle werden nach den Fundorten beschrieben und teilweise in gaten Abbildungen demonstriert. Fritz Juliusberg (Posen).

Chvostek, F., Wien. Xanthelasma und Ikterus. Wiener klin. Wochenschr. 1910. Nr. 46.

Bei der Bedeutung des Nervus sympathicus für die Gefäßinnervation der Hant und ihre Trophik muß jene Störung, welche die tür die lipoide Anreicherung der Zellen notwendige Dekonstitution der Kutiszellen herbeiführt, im Bereiche des sympathischen Systems gesucht werden. Für das Zustandekommen der Xanthelasmen bei Ikterus sind demnach die Bedingungen gegeben, wenn zu einer durch eine hepatale Affektion verursachten Störung im Fettstoffwecksel, vielleicht einer dadurch bedingten Überladung des Blutes mit Cholesterin, eine Störung im Bereiche des Sympathikus hinzutritt. Sind beide Momente vorhanden und das gilt für die große Mehrzabl der Fälle, so sind die Bedingungen für das Auftreten der Xanthelasmen die günstigsten. Neben den nervösen Einflüssen kommen auch andere die Zellen schädigende Momente in Betracht, vor allem mechanische. Aber alle außer dem nervösen Einflusse zur Geltung gelangenden schädigenden Momente, kommen, wenn überhaupt, so nur höchst 
selten, allein in Betracht (Erysipel), meist kommen sie nur bei gleichzeitiger Anwesenheit der nervösen Störung, diese unterstützend, zur Geltung.

Viktor Bandler (Prag).

Stancanelli, P. Klinischer, histologischer und kritischer Beitrag zum Studium des Xanthelasma. Giorn. internaz. d. Scienze med. Heft 24. 31. Dez. 1910.

Nach eingehenden Studien kommt Stancanelli zu folgenden Schlüssen :

1. Das Xanthelasma vulgare stellt mit all seinen zablreichen morphologischen und klinischen Varietäten (umschriebenes, diffuses, flaches, tuberöses, tumorartiges Xanthelasma) einen gut definierten und klinisch autonomen Krankheitstypus dar.

2. Weit entfernt davon, konstant einförmig zu sein, bietet es vom histopathologischen Gesichtspunkte aus einen evolutiven Zyklus dar, der ziemlich charakteristisch scheint und in dem die Läsionen in den verschiedenen Phasen, in denen die Dermatose sich klinisch findet, variieren.

3. In seiner Entwicklung kann man drei verschiedene Perioden unterscheiden nämlich: a) Periode der Proliferation, die vor sich geht auf Kosten der endothelialen Elemente der Kapillaren und der Lymphgefäße des Bindegewebes und die za einer Intiltration führt, die hauptsächlich aus epitbeloiden Zellen besteht, welche in einem gegebenen Augenblick die Bildung typischer Riesenzellen veranlassen können; b) Periode der Degeneration und Nekrobiose, mit fettiger Infiltration der proliferierten Elemente, mit trüber Schwellung, Chromatolyse, Pigmentdegeneration, denen ein Zustand fortscbreitender Atrophie folgt, zum Teil auch verursacht durch die Alterationen der Kapillar. wandungen, die mit dem Fortschreiten der Affektion immer auffälliger werden und eine ausgesprochene Tendenz zur Atresie und Obliteration zeigen; c) stationäre Periode, in der die Läsion aus einem Gewebe besteht, das einer eigentlichen Struktur und wahrer Vitalität ermangelt und welches das Aussehen und die Reaktionen der hyalinen und kolloiden Substanz darzubieten scheint und welches, trotzdem es im Derma nach Art eines Fremdkörpers eingeschlossen bleibt, in der Mehrzahl der Fälle keine besonderen interstitiellen oder peripheren Reaktionserscheinungen hervorruft.

4. Die fettigen Granulationen der Proliferationselemente (Xanthelasmazellen von $\mathrm{Chambard)}$ stellen kein konstantes morphologisches Attribut dar, denn ihre Anwesenheit in allen Fällen und in allen Augenblicken der Affektion ist nicht festzustellen.

Aus diesem Grunde kann man kaum eine Analogie zwischen Xanthelasma und Fettgewebe im embryonalen oder erwachsenen Zustande aufrecht erhalten.

5. Dieselben Elemente können nicht nachweisbar sein in den Läsionen einer vorgerückten Phase, in denen sie ersetzt werden durch amorphes und atypisches Gewebe. 
6. Die gelbe Färbung des Xanthelasmas muß - anstatt in Verbindung gebracht zu werden mit fettiger Infiltration - zurückgeführt werden auf ein besonderes Pigment, das keine Eisenreaktion gibt, das analog dem Lutein scheint und sich in der papillären und subpapillären Schicht des Dermas, zuweilen noch in den tieferen Schichten des Corpus Malpighii findet und das sich zu bilden scheint aus dem Zerfall der epitheloiden in der subepidermoidalen Schicht gelegenen Elemente, dort wo im normalen Zustande und in mehreren Krankheitsprozessen die Formation oder das Depot von Pigment zu finden ist.

7. Wie vom klinischen so scheint auch vom histopathologischen Gesichtspunkte aus eine fundamentale Differenz zwischen dem zirkumskripten flachen Xanthelasma der Lider und dem diffusen nicht haltbar.

8. Es ist auch kein fundamentaler Unterschied zwischen flachen und tumorartigen Formen aufrecht zu erhalten. Denn wabrscheinlich sind die morphologisuhen Varietäten auf die verschiedene Intensität und Dauer der Wirkung des pathogenen Agens, auf besondere Bedingungen lokaler Prädisposition, auf etwaige interstitielle oder periphere Reaktionsphänomene zu beziehen.

9. Das systematische Studium der histologischen Befunde in den verschiedenen Entwicklungsphasen der Affektion scheint die Auffassung, als ob es sich um eine Dermatose mit neoplastischem Typus handelte, nicht zu unterstützen.

10. Dagegen erfährt die Auffassung, als ob es sich beim Xanthelasma urn eine endogene Toxidermie mit persistierenden klinischen Manifestationen handelte, nicht nur keinen Widerspruch durch die histologische Untersuchung, wenn man sich von den verschiedenen Befunden in Beziehung zu den verschiedenen Perioden, in denen die Affektion sich findet, Rechenschaft ablegt, sondern diese Auffassung erhält sogar dadurch eine kräftige Stütze.

11. Diese diathesisch-dystropische Theorie scheint uns noch annehmbarer, insofern als sie uns früher schwierig zu erklärende Erscheinungen klar macht und - was wichtiger ist - in einem einzigen Krankheitsbilde die verschiedenen Formen von Xanthelasma vulgare und sehr wahrscheinlich auch das Xanthelasma diabeticum au vereinigen erlaubt.

J. Ull mann (Rom).

Wolters. Beitrag zur Kenntnis der Urticaria perstans papulosa. Unnas Dermatol. Studien (Unna-Festschrift Bd. I), Bd. XX. pag. 566 .

Wolters geht aus von der Arbeit von F. J. Pick über Urticaria perstan (Prager Zeitschrift für Heilkunde, 1881), um eingehend über die bisher bekannten Fälle dieser Erkrankung zu referieren.

Der eigene Fall von Wolters betrifft einen Mann, der schon seit 7 Jahren an der Hautkrankheit leidet. Der Ausschlag ist am stärksten entwickelt an den Vorderarmen, den Weichen und den Oberschenkeln, wo dichtgedrängte Papeln $z u$ sehen sind, während sie sich weniger zahlreich auf Brust, Rücken und an den Unterschenkeln finden. Frei sind 
die Hände, die Füße, die Ellenbogen, Knie, die Nates, die Genitalien und der Kopf. Die einzelne Effloreszenz stellt sich als eine derbe, nur minimal abschilfernde, zum Teil zerkratzte und mit einer Blutkruste bedeckte Papel dar, die in der Gröbe zwischen einer Linse und einem kleinen 20 Pfennigstück schwankt und auf der Brust auch die eines 10 Pfennigstücks erreicht. Die Farbe ist blaßrot, teilweise lebhafter rot, teilweise bräunlich. Die erfolgreiche Behandlung bestand in Unnas Sublimatkarbolsalbe und Injektionen von Atoxyl $0 \cdot 1-0 \cdot 2$ pro die, später in Arsen 1-6 $\mathrm{mg}$ pro die. Unter dieser Therapie gingen die Effloreszenzen deutlich zurück. Die histologische Untersuchung einer Papel vom Arme ergab: starke Hyperkeratose mit färbbaren Kernen in den schon verhornten Zellen, die Keratohyalinschicht war in den zentralen Partien etwas undeutlicher, die eigentlichen Veränderungen saßien aber im Korium; hier fanden sich Anhäufungen von Wanderzellen und Leukozyten und eine massige Einscheidung aller Lymph- und Blutgefäße durch Konglomerate kleiner, rundlicher, einkerniger protoplasmaarmer Zellen. Die Gefäße waren mehr oder weniger dilatiert.

Fritz Juliusberg (Posen).

v. Notthafft, Freiherr. Lichen atypicus. Unnas Dermatolog. Studien (Unna-Festschrift Bd. II), Bd. XXI. p. 44.

v. Notthafft beschreibt unter dieser Bezeichnung $\mathbf{2 w e i}$ gleichartige knötchenförmige Ausschläge bei zwei weiblichen Patienten im Alter von 21 resp. $18 \mathrm{Jahren}$, die in keines der bekannten Lichenbilder paßten und sich gegenüber der üblichen Therapie sehr refraktär verhielten. Sie wichen prompt auf eine lokale Salizylapplikation. Der Ausschlag hatte überhaupt keinen Einfluß auf das Allgemeinbefinden und stellte nur eine kosmetische Störung dar. Die Knötchen hatten sich schleichend und schuppweise entwickelt. Sie heilten ohne Narben und Pigmentierung ab. Mikroskopisch war ein lichenförmiges, ziemlich begrenztes, papillares und subpapillares Infiltrat mit Gefäßerweiterung da, doch erreichte es nicht die Mächtigkeit der Lichen ruber-Platte. Die charakteristischen Veränderungen im Papillarkörper und Stratum spinosum fehlten volkommen. Es fehlte ferner der Juckreiz und die innere Arsentherapie versagte. Die Knötchen waren nicht polygonal, sondern rund und hatten keine Delle. Nach der Ansicht des Autors gehören die Fälle einem bisher nicht geschilderten Krankheitstypus an, am ehesten würde der Krankheit der Namen Lichen simplex chronicus entsprechen.

Fritz Ju liusberg (Posen).

Broers, J. Ein ungewöhnlicher Fall von Lichen. Unnas Dermatolog. Studien (Unna-Festschrift Bd. II), Bd. XXI. p. 41.

Broers Fall von Lichen der Unterschenkel stellt einen Fall von verrukősem Lichen ruber vor, bei dem keine typischen Planuspapeln vorhanden waren.

Fritz Juliusberg (Posen).

Haase, Markus. Eine chronische juckende papulöse Eruption der Achselhöhlen, der Schamgegend und der Brust. The Journal of the Amer. Med. Assoc. 1911. 21. Jan. p. 174. 
Ha a se beschreibt einen Fall von Neurodermitis chronica circumscripta der Achselhöhlen, der Schamgegend und der Brust. Der Fall bietet klinisch keine Besonderheiten, doch ist er sehr sorgfältig histologisch untersucht worden. Die mikroskopische Untersuchung eines Stückes aus der Achselhöhle ergab: eine starke Akanthose, die besonders um die Schweißdrüsengänge deutlich war, eine dicke Hyperkeratose an der Ausmündung der Gänge. Es bestand ein extra- und intrazelluläres ödem mit einer Schrumpfung um die Kerne der Stachelzellen und der teilweisen Bildung kleiner Bläschen. Im papillären und subpapillären Teile des Koriums bestanden ansgesprochene Degeneration und Ödem, das elastische Gewebe nahm in diesen Teilen nicht die gewöhnliche Färbung an. Es bestanden herdweise Infiltrationen von Lymphozyten und Plasmazellen um die Gefäße und Schweißdrüsen. An einigen Arterien des Koriums fand sich eine hyaline Degeneration mit Atrophie der Wandkerne, aber die ausgesprochenste Veränderung war die Dilatation der Schweißdrüsen zugleich mit einer Degeneration der Wandzellen. In einigen Tubulis fanden sich runde Körper, deren Natur nicht festzustellen war.

Fritz Juliu sberg (Posen).

Menage, H. E. Ein neurodermatologischer Fall. New Orleans Medical and surgical Journal. Dez. 1910. Ref. The Journal of the Americ. Med. Assoc. 1910. 24. Dez. p. 2270.

Menage berichtet über einen Fall von spontaner Gangrän der Haut, mit öfters beobachteten Eruptionen, bei dem es nicht gelang, das Agens festzustellen, mit dem sich die Patientin die Läsionen beibrachte. Fritz Juliusberg (Posen).

Buschke, A. und Fischer, W. Keratodermia maculosa disseminata symmetrica palmaris et plantaris. Ikonographia dermatologica. Fasc. V. Tab. XXXVII.

Die Erkrankung des 40jähr. Patienten, dessen Anarunese belanglos ist, begann vor 20 Jahren und erstreckt sich auf Flachhände und Fußsohlen. Es finden sich daselbst zahlreiche 1-5 $\mathrm{mm}$ große, der Epidermis angehörige Effloreszenzen. Die kleinsten, über das Hautniveau kaum erhaben, zeigen eine glänzende Oberfläche, weißliche Farbe und Fehlen der normalen Hautfältelung, die größeren deutliche, gelbliche Farbe, völlige Verwischung der papillären Leisten, glatte Oberfläche, vereinzelte auch eine flache Einsenkung im Zentrum. Die größten Effloreszenzen besitzen meist eine oblonge oder polygonale Form, entsprechend den Fallungslinien der Epidermis und tragen zum großen Teile eine zentrale Delle von bläulichroter Farbe. Die Gebilde liegen alle in vollkommen normaler Haut, zeigen keinen erythematösen Hof und lassen keinen $\mathrm{Zu}$ sammenhang mit den Schweißdrüsen erkennen. Die Fußsohlen, an denen das Fubgewölbe frei ist, zeigen neben den oben beschriebenen Effloreszenzen noch kleine, längliche, schwarzbraune Einlagerungen in die normale Haut, die den Eindruck machen, als seien sie in dieselbe hineingepreßt; löst man ein solches Körperchen heraus, so bleibt eine entsprechende Einsenkung der Haut zurück; solche Einsenkungen finden sich 
auch am Außenrande der Sohle und an den Fersen. Die Nägel sind normal.

Die histologische Untersuchung ergab das Fehlen jeglichen entzündlichen Infiltrates und normales Verhalten der elastischen Fasern. Der Proz $B$ beschränkt sich auf den epithelialen Anteil der Haut; die epithelialen Schichten sind gleichmäßig verdickt, der Verhornungsprozeß normal, nirgends Spuren von Parakeratose; die Keratohyalinsehicht ebenfalls um einige Lagen verbreitert, die Hornschichte selbst, ebenfalls verbreitert, in ihrer Struktur nicht verändert. Die Schweißdrüsen zeigen in ihrem ganzed Verlaufe keine Veränderung.

Verf. besprechen die schon bekannten, von Besnier, Hallopeau und Claisse, Mautoux, Balzer und Germain, Beurmann und Gougerot, endlich von Balzer und Boyé beschriebenen Keratodermien der Flachhände und Fußsohlen und gelangen zu dem Schlusse, daß es sich in ihrem Falle um einen neuen Typus dieser Krankheitsform handle, für welchen sie den im Titel gegebenen Namen vorschlagen.

Wilhelm Balba n (Wien).

Bonne, Georg. Neue Beiträge zur klinischen Würdigung des Eczema seborrhoicum Unna. Unnas Dermatologische Studien (Unna-Festschrift Bd. I), Bd. XX. p. 423.

Bonne weist auf seine früheren Arbeiten hin, in denen er sich über die Wirkung des Eczema seborrhoicum auf den Gesamtorganismus, über das seborrhoische Ekzem als Konstitutionsbasis der sog. Skrofulose und über die klinische Bedeutung des seborrhoischen Ekzems für die Entstehung der Nasenrachenvegetationen und der Karzinome geäußert hat. Er hebt in dieser Arbeit hervor, daß bei fast allen Kindern, die mit der Hypertrophie der Rachenmandeln behaftet sind, noch Ekzemreste auf der äußeren Haut nachweisbar sind oder ein Ekzem früher bestanden hat oder die Kinder aus ekzematöser Familie stammen. Nicht bloß die Nasenrachengranulationen, sondern auch Katarrhe der Bronchialschleimhant stehen mit dem seborrhoischen Ekzem im ursächlichen Zusammenhang. Ferner ist das Eczema seborrhoicum eine der Hauptursachen, durch deren chronische Reizwirkung die Entstehung der Karzinome begünstigt wird. Fritz Juliusberg (Posen).

Hodara Menahem. Über einen der seltenen und atypischen Fälle von Epidermolysis bullosa (Köbner). Unnas Dermatologische Studien (Unna-Festschrift Bd. II), Bd. XXI. p. 609.

Man unterscheidet, wie Hodara ausführt, zwei Formen der Epidermolysis bullosa, die typische Epidermolysis bullosa hereditaria und eine zweite Form, die verschieden benannt worden ist, Pemphigus congenitalis, Ichthyosis mit bullösen Schüben etc. Manche Autoren identifizieren beide Formen. In dem vorliegenden Falle, der sehr genau beschrieben und eingehend histologisch studiert worden ist, handelt es sich um einen Fall, der zum großen Teil den typischen Fällen ähnelt, aber histologisch eher in die zweite Gruppe gehört. Die Ausführungen sind zum kurzen Referat nicht geeignet. Fritz Juliusberg (Posen). 
Jaquet, Isucien und Rousseau, Decelle. Sur un cas de pelade d'origine dentaire. Unnas Dermatolog. Studien (Unna-Festschrift Bd. II), Bd. XXI. p. 480.

Jacquet erinnert an seine Arbeiten über die Beziehungen der Alopecia areata zu Krankheiten der Zähne. Seine Theorie auch in Frankreich nicht allgemein anerkannt, hat in Deutschland nur eine Nachprüfung erfahren (cf. Bettmann, dieses Archiv 1904. Bd. LXX). Ein neuer sorgfältig beobachteter Fall soll die Jacquetsche Hypothese stützen. Diese ist folgende:

Die Alopecia areata steht in Beziehungen zu einem Symptomenkomplex, der durch dieselben Reize hervorgerufen wird. Diesen setzen zusammen:

1. eine direkte lokale Atmosphäre (Störungen durch Übermaß, dann durch Defektwerden), die die verschiedenen Funktionen der Haut betrifft, Organen.

2. eine indirekte lokale Atmosphäre in verschiedenen anderen

Dieser Symptomenkomplex wird hervorgerufen durch gewisse organische Überreizungen, die von ganz bestimmten Apparaten ausgehen: das Nervenzentrum, die gastro-intestinalen, broncho-pulmonalen, genitalen, Ohr- und Rhinopbarynx-Systeme, besonders aber ist das Zahnsystem geeignet, am behaarten Kopf Reizungen hervorzurufen. Diese Reize werden besonders dann pathogen und alopezieerzeugend, wenn der behaarte Kopf durch eine Reihe von Zuständen besonders prädisponiert ist. Diese Prädisposition kanu durch allgemeine Zustände bedingt sein, mangelhafte Blutbeschaffenheit, große Infeltionen, nervöse Erschütterungen etc. oder durch lokale, Abszesse, Furunkel, Narben etc. Besonders wirksam ist das Zusammentreffen gleichzeitiger innerer und äulBerer Reize.

Fritz Juliusberg (Posen).

Buschke, A. Weitere Beobachtungen über die physiologischen Wirkungen des Thallium. Dtsch. med. Wochenschr. Nr. 4. 1911.

Die Ergebnisse von Buschkes mit Thallium vorgenommenen Tierexperimenten sind etwa folgende: Ganz kleine Dosen von Thalliumsalzen, besonders Thallium aceticum und carbonicum erzeugen bei Mäusen, Kaninchen, Ratten und Affen eine Alopezie, welche den bei Menschen auftretenden Nebenerscheinungen entspricht und welche sich bei Mäusen und Kaninchen auf Rücken und Kopf beschränkt, bei Ratten aber universell wird. Vergleishbar der Hypotrichosis congenita beim Menschen konnte durch Thallium auch bei Ratten eine, allerdings nicht stationär bleibende Hypotrichosis congenita erzeugt werden. Nach den Beobachtungen über seine antihydrotische Wirkung liegt der Angriffspunkt des Thalliums nicht peripherisch, sondern im zentralen Nervensystem. Eine Wirkung des Thallium auf experimentelle Tiersyphilis war nicht zu erkennen. Max J o seph (Berrlin). 
Brocq, I. Über die „dermatites polymorphes érythémato-vésiculobulleuses non douloureuses". Unnas Dermatolog. Studien (Unna-Festschrift Bd. 1), Bd. XX. p. 13.

Broc $q$ kommt in seinen interessanten Ausführungen zu folgenden Schlüssen: Wenn man die Frage so stellt, ob unter die "dermatites polymorphes douloureuses" auch Fälle gehören, die nicht das geringste schmerzhafte $\mathrm{Phänomen} \mathrm{haben,} \mathrm{so} \mathrm{ist} \mathrm{die} \mathrm{Fragestellung} \mathrm{nicht} \mathrm{zweckmäßig.}$ Würde man die Ätiologie und Pathogenese dieser Affektionen kennen, so wäre es sehr einfach: Die Krankheitsgruppe wäre durch das pathogene Agens bestimmt und alle Hautaffektionen, die durch dieses Agens zustande kämen, müßten in die Gruppe eingereiht werden, wie auch ihre Symptome wären.

Aber dem ist nicht so. Die "dermatites polymorphes douloureuses" so wie die "dermatites herpétiformes" sind nicht wirkliche Krankheitsgruppen: es sind von den Autoren geschaffene Symptomenkomplexe, für provisorische Klassifikation der pathologischen Tatsachen und man darf nur Beobachtungen einreihen, die die Charaktere dieser Symptomenkomplexe aufweisen.

Wenn man will, kann man einen ungeheuren Symptomenkomplex schaffen: die „dermatites polymorphes", der alle die Fälle umfaßt, die durch erythematöse, vesikulöse, bullöse Eruptionen charakterisiert sind.

Dieser Komplex umfaßt Fälle mit akutem Charakter, rezidivierenden oder nicht rezidivierenden und solche mit chronischem Charakter mit folgenden Schüben. Diese Komplexe sind umschriebener, wie der vorhergehende und in ihm enthalten.

Außer diesen beiden Komplexen gibt es noch andere mehr umschriebene, präziser definierbare, wie die folgenden:

Unter den akuten Fällen sind die einen von wenig oder gar keinen subjektiven, schmerzhaften Erscheinungen begleitet, das sind die wahren polymorphen Erytheme; andere haben intensive schmerzhafte subjektive Erscheinungen, das sind die "dermatites polymorphes douloureuses aigues"; zwischen beiden Gruppen gibt es Übergangsfälle.

Ebenso fehlen bei den chronischen Fällen, viel seltener bei Erwachsenen, viel häufiger bei Kindern unter 15 Jahren, schmerzhafte subjektive Symptome und das sind dann entweder die "dermatites polymorphes chroniques non douloureuses" oder die „dermatites herpétiformes non douloureuses"; andere haben im Gegenteil sehr intensive subjektive schmerzhafte Erscheinungen und das sind die "dermatites polymorpbes douloureuses chroniques"s oder die "dermatites herpétiformes typiques". Zwischen allen diesen Typen kommen Übergangsfälle vor. Fritz Juliusberg (Posen).

Dreuw. White spot disease oder Sclerodermiacircumscripta? Unnas Dermatolog. Studien (Unna-Festschrift Bd. II), Bd. XXI. pag. 214.

Dreuw berichtet über einen auch histologisch gut studierten Fall von der Form der „White spot disease“, die ins Gebiet der Sclerodermia 
circumseripta fällt. Um Irrtümern vorzubeugen, sei darauf hingewiesen, daß, wie auch in den betreffenden Arbeiten hervorgehoben wurde, der Fall Hoffmann-Juliusberg und der Fall Juliusberg identisch sind. Diesem Falle gleichen vollständig die Fälle von Riecke und der obige Fall von Dreuw. Ferner gehören in dieselbe Gruppe die auch histologisch untersuchten Fälle von $Z$ arubin, Warde, MontgomeryOrmsby, sowie die nicht histologisch untersuchten Fälle von Macleod, Sherwell und Herxheimer. Dreuw schlägt vor, diese Fälle von Weißfteckenkrankheit zusammenzufassen als „Sclerodermia circumscripta Un $n a^{4}$. Fritz Juliusberg (Posen).

Sedgwick, R. E. Über einen Fall von Sclerema neonator a m. The Lancet 1911. 4. Februar. p. 301.

Sedgwick berichtet kurz über einen letal endigenden Fall von Sclerema neonatorum. Fritz Juliusberg (Posen).

Jamieson, W. Allan. Morphoea guttata, v. Scleroderma. Ikonographia dermatologica. Fasc. V. Tab. XXXIX.

Die 39jähr. Patientin zeigte in der Gegend beider Klavikeln zahlreiche, leicht elevierte, elfenbeinweiße, glatte, glänzende, von einem schmalen, rosaroten oder violetten Hofe umgebene Flecke. Leider erschien die Kranke nicht wieder und gestattete keine Exzision. Es handelt sich zweifellos um einen Fall von Morphoea guttata, von den Engländern und Amerikanern "White spot disease“ genannt.

Wilhelm B a lban (Wien).

Jordan, Arthur. Ein Fall von idiopathischer Hautatrophie (Erythromelie Pick). Unnas Dermatolog. Studien (Unna-Festschrift Bd. II), Bd. XXI. p. 330.

Bei Jordans Patientin, einer 53jährigen Frau, traten die Hautveränderungen im AnschluB an eine Landfahrt bei strenger Kälte auf zunächst an den Händen, dann an dem übrigen Körper. Es entwickelte sich eine Röte, die zu einer Atrophie führte. Histologisch fand sich: Verdickung der Hornschicht, Fehlen der Papillarschicht, undeutliche Konturen des elastischen Gewebes in der subpapillaren Schicht, Verminderung der Schweiß- und Talgdrüsen wie der Haarfollikel, kleinzellige Infiltration in der Umgebung der Gefäße. Ungewöhnlich ist die Atrophie verschiedener Muskeln in diesem Falle. Fritz Juliusberg (Posen).

Saenger, Alfred. Über symmetrische Gangrän. Unnas Dermatolog. Studien (Unna-Festschrift Bd. II), Bd. XXI. p. 276.

Sa euger berichtet äber einen der seltenen Fälle von Raynaudscher Krankheit, bei dem lediglich die Ohren befallen waren. Es handelte sich um einen 12jühr. Knaben, bei dem die Krankheit seit 1/2 Jahre bestand. Die Krankheitsherde saßen an den Rändern beider Ohren. Die Untersuchung des Nervensystems ergab die Steigerung sämtlicher Sehnenreflexe. Es bestanden die Zeichen der nervösen Asthenopie. Der Fall ist auch dadurch ausgezeichnet, daß das von $R$ ay $n$ a $\mathrm{u} d$ aufgestellte Stadium der lokalen Synkope fehlte. Sänger nimmt an, daß in den oberen Zervikalsegmenten und zwar in den hinteren und seitlichen Partien der 
granen Substanz eine Erregung des vasomotorischen Zentrums eintritt, wodurch ein Krampf der Gefäße bedingt wird. Durch Fortpflanzung der Erregung auf den nicht weit entfernten Vaguskern, ließe sich vielleicht auch das in diesem Fall vorhandene Erbrechen erklären. In einem zweiten Falle von symmetrischer Gangrän, den der Autor post mortem untersuchen konnte und bei dem beide Füße affiziert waren, handelte es sich in der Hauptsache um eine auf den Sakralteil des Rüekenmarks beschränkte Myelomalazie. Da in diesem Falle auch die hintere und seitliche graue Substanz im Sakralmark zerstört war, die man als den Sitz der vasomotorischen Bahnen anzusehen hat, so ist es möglich, daß auch der erste Angriffspunkt der traumatischen Läsion an dieser Stelle eingesetzt und somit $A n l a ß$ zu heftigem Gefäßkrampf in den Füßen gegeben hat. Dieser Fall von symmetrischer Gangrän, der allerdings nicht die Charakteristika der Raynaudschen Krankheit hatte, stützt die Auffassung Raynauds, daß eine Reizung eines bestimmten vasomotorischen Zentrums im Rückenmark anzunehmen sei. Wir können uns im Rahmen des Referates nur auf diese kurzen Angaben beschränken, die Arbeit enthält noch weiteres kasuistischesMaterial zu der Frage der symmetrischen Gangrän.

Fritz Juliusberg (Posen).

Richter, Wilhelm. $Z$ ur Impetigo herpetiformis. Unaas Dermatolog. Studien (Unna-Festschrift Bd. I), Bd. XX. p. 189.

$\mathrm{Richters}$ Fall des zuerst von $\mathrm{Hebra} 1872$ beschriebenen Impetigo herpetiformis betrifft eine 22jähr. Frau, die vor 8 Monaten die letzten Menses gehabt hat und seit 4 Monaten Kindsbewegungen verspürt. Die Hautkrankheit begann vor 5 Wochen mit Bläschen über der rechten Leistenbeuge. Bei der Aufnahme finden sich neben mehreren borkigen Flächen Bläschen- und Pustelgruppen, die sich ohne Störungen des Allgemeinbefindens weiter ausbreiten. Nach der Geburt kommt es zu Temperaturerhöhungen und zu Kräfteverfall, wobei 8 Tage nach der Geburt die Hauterscheinungen ihren Höhepunkt erreichten. Mit Ausnahme der Hände, der Füße, des Gesichtes und des behaarten Kopfes, deren Haut leicht infiltriert ist, ist der ganze Körper ergriffen. Unter Eintrocknen beginnen die krustösen Auflagerungen sich abzustoßen. Es kommt zu völliger Abheilung. Die mikroskopische Untersuchung eines exzidierten Hautstückchens ergab Blasenbildung in den mittleren Schichten der Epidermis, stellenweise Verflüssigung des Rete Malpighii. Der Inhalt der Bläschen ist reich an Eiterkörperchen. Der Papillarkörper ist im Bereiche der Bläschen ödematös gequollen, hie und da auch eitrig infiltriert.

Fritz Juliusberg (Posen).

Gougerot und Salin. Zoster mit multiplen Lokalisationen und Immunität bei Z oster. Gaz. des hopitaux 1910. p. 1785.

In einem Fall von Zoster im Gebiet des 3. rechten Lumbalnerven, der starke subjektive Beschwerden verursachte, folgte 5 Tage nach der ersten Eruption eine zweite doppelseitige im Gebiet des 8. Zervikal- und 1. Dorsalnerven. Dieser zweite Zoster dauerte nur 3 Tage und verschwand dann, während der erste noch bestand und schmerzhaft war. Der abge- 
schwächte Verlauf der zweiten Eruption wird auf Immunitätsvorgänge zuräckgeführt. Der Zoster lokalisiert sich deswegen gewöhnlich nur auf ein Nervengebiet, weil rasch Immunität eintritt und ein Weitergreifen der Infektion verbindert. Multiple Eruptionen sind durch besonders intensive Infektion za erklären, die sich ausbreitet, bevor die Autoimmunisation vollendet ist. Da in diesem Falle nicht benachbarte, sondern entlegene Ganglien von der zweiten Erkrankung befallen wurden, kann man annehmen, $d a B$ die Immunität sich lokal progressiv ausbreitet.

\section{F. Lewandowsky (Hamburg).}

Bittorff, A. Herpes zoster und Nierenkolik. Dtseh. med. Wochenschrift. 1911. Nr. 7.

Bei der 22jähr., bisher gesunden Patientin Bittorfs entwickelte sick im AnschluB an eine sehr schmerzhafte Nierenkolik, der bereits seit Monaten mehrere ähnliche Anfälla vorangegangen waren, ein Herpes zoster im Bereich des 11. rechten Dorsalsegments. Der Kolik lag eine rechtseitige Hydronephrose zugrunde. Auch in anderen Fällen fand sich bei Erkrankung innerer Organe in den entsprechenden hyperalgetischen Zonen vermehrte vasomotorische Erregbarkeit. Bei Aortenerkrankungen können Schmerzen in den byperalgetischen Zonen der Ulvarseite des 1. Vorderarmes ein beachtenwertes Symptom bilden.

Max J o s e ph (Berlin).

Schmey, Fedor. Über einen eigenartigen Fall von Purpura mit tödlicher Gehirnblutung im Kindesalter. Dtsch. med. Wochenschr. 1907. Nr. 7.

Der 8jähr., muskulös aber skrofulös erscheinende Knabe, kam in die Behandlung $\mathrm{Schmeys}$ wegen blutigem Auswurf und Schwellung der Halsdrüsen. Einige Zeit nachher trat eine Magenblutung auf, außer Mattigkeit keine subjektiven Beschwerden. 3 'lage später erschienen an Armen und Beinen schwärzliche, in der Mitte harte, erhabene Flecke. Fast plötzlich trat tiefes Koma ein, eine kolossale Lebervergrößerung wurde festgestellt, nach 4 Stunden erfolgte bei einer Blutung aus dem Munde, aber ohne jede Konvulsion, der Tod. Es handelte sich offenbar um eine Blutung in die Gehirnsubstanz. Die skrofulöse Veranlagung, die vielleicht auch tuberkulöser Natur war, war möglicherweise ätiologisch in Betracht zu ziehen.

Max Joseph (Berlin).

Macmillan, Stewart. Ein Fall von Henochs Purpura oder Purpura abdominalis. The Brit. Med. Journ. 1910. 26. Nov. p. 1718.

Macmillan berichtet über einen Fall von Henochscher Purpura, der nach Behandlung mit Kalziumlaktat zur Heilung kam.

Fritz Juliusberg (Posen).

Collins, Josef. Pellagra. Kurzer Bericht äber die Theorien, die Ursacheder Pellagra, mit Mitteilung eines Falles, der in New-York city vorkam. Medical Record. 1911. 7. Jan. p. 8. Nichts Neues. Mitteilung eines Falles von Pellagra. 
Price, R. P., Ravogli u. a. Diskussion über Pellagra. The Journ. of the Amer. Med. Assoc. 1911. 28. Januar. p. 251.

Die Arbeit betrifft eine Diskussion über Pellagra, die auf der St. Louis-Tagung der Americ. Med. Assoc. in der Sektion für Dermatologie gehalten wurde. Die Sitzung enthält zahlreiche kasuistische Mitteilungen, Debatten über die Ätiologie und andere die Pellagra betreffenden Fragen, die im Referat nicht wiedergegeben werden können. Fritz Juliusberg (Posen).

Tucker, Beverley. Pellagramit analytischer Studie von 55 sporadischen Fällen. The Journal of the Americ. Med. Assoc. 1911. 28. Januar. p. 246.

Tucker kommt in seiner Arbeit über Pellagra zu folgenden Schlüssen: 1. Pellagra kommt in jedem Alter von der Kindheit bis zum Greisenalter vor. 2. Obgleich in den Südstaaten die Neger in den niederen Schichten überwiegen, ist doch Pellagra häufiger bei den Weißen. 3. Die Krankheit befällt hauptsächlich die niederen Schichten, aber sie kommt auc $b$ bei Menschen mit guter Hygiene und in günstigen sozialen Verhältnissen vor. 4. Die Krankheit ist weit verbreitet und tritt nicht in Form lokaler Epidemien auf. 5. Die Krankheit wurde häufiger in ländlichen Distrikten als in. Städten beobachtet. 6. Die Majorität der Fälle trat im Frühjahr und Sommerbeginn auf. 7. Die gastro-intestinalen Erscheinungen, besonders die Diarrhoe, sind gewöhnlich die ersten Symptome der Krankheit. 8. Die Aufnahme von Mais oder Maisprodukten, mögen sie verdorben sein oder nicht, ist nicht allein die Ursache der Pellagra. 9. Patienten, deren Konstitution durch üble Gewöhnungen oder chronische Krankheiten geschwächt ist, sind nicht mehr empfänglich für die Pellagra als Kräftige. 10. Die Handrücken sind bei den Hautaffektionen der Pellagra immer beteiligt und zwar in symmetriseher Weise. 11. Sonnenbestrahlung bat keinen Einfluß auf das Entstehen der Hauterscheinungen. 12. Die Stomatitis ist immer ein konstantes Symptom. 13. Die Symptome der Nerven- und Geistesorgane entsprechen nicht denen, die man bei den bekannten Nerven- und Geisteskrankheiten findet. 14. Die nervösen und geistigen Störungen stellen kejne klinische Einheit dar. 15. Die Augensymptome sind nicbt pathognomonisch. 16. Abmagerung ist konstant. 17. Die speziellen Sinnesorgane sind nur gelegentlich affiziert. 18. Die Pellagra ist an und für sich nicht eine fieberhafte Erkrankung; tritt Fieber bei ihr auf, so ist dieses häufig durch irgendeine Komplikation verursacht. 19. In den meisten Fällen findet sich eine mäßige Anämie. 20. Das Herz, die Lungen und die Genitourinal-Organe werden bei der Pellagra nicht speziell affiziert. 21. Untersuchungen des Urins, der Fäzes und des Blutes ergeben nichts pathognomonisches für die Pellagra. 22. Die Ursache der Pellagra ist unbekannt und das Studium der vom Autor beobachteten Fälle wirft kein positives Licht auf die Ätiologie. Es sind Patienten darunter, die keine Kornprodukte aßen. Sonnenlicht ist kein'ätiologischer Faktor. Bei den Fällen konnten weder Parasiten noch Toxine, noch Insekten isoliert werden, die als ätiologischer 
Faktor gelten konnten. 23. Die Krankheit ist durch den gewöhnlichen Kontakt nicht übertragbar. 24. Drei große Systeme werden affiziert: der Verdauungstraktus, die Hautoberfläche und das zentrale und periphere Nervensystem, wobei das Befallensein in der genannten Ordnung auftritt. 25. Rezidive kommen in über der Hälfte der Fälle vor. 26. Der Tod erfolgt häufig bei der ersten Attacke. 27. Das Studium der Krankheit in Amerika ist $z u$ jung, um die Mortalität $z u$ bestimmen. Sie beträgt wahrscheinlich 50\% während der ersten 2 Jahre. 28. Bei diesen Fällen kann man nie sagen, ob ein Patient nur scheinbar geheilt ist. 29. Bisher hat man keine spezifische Behandlung für die Krankheit gefunden; die gewöhnlich gebrauchten Heilmittel haben nur zweifelhaften Wert; Hexamethylenamin hat möglicherweise gute Wirkung.

Fritz Juliusberg (Posen).

Bréaudat und Denier. Du son de Paddy, dans le traitement préventif et curatif du Beriberi. Annales de l'institut Pasteur. Tome XXV. Nr. 2. 25. Februar 1911.

Die Verfasser beobachteten die Epidemie von Beriberi am Cap Saint Jaques vom Juni 1909 bis April 1910 und kommen zu folgenden Resultaten:

Die klinische Form dieser Epidemie zeigte sich sowohl als trockene als auch als feuchte Form der Beriberi mit besonderer Beteiligung des Magens.

Die Kleie von Paddy (Reisart), auch in großer Dosis gegeben, erzeugte keinerlei Verdauungsstörung.

In Dosen von $40 \mathrm{~g}$ täglich zeigt sie nur eine präventive Wirkung ; für die kurative Wirkung ist die Dose zu klein. Ohne die gewöhnliche Nahrung der Eingeborenen zu ändern hat sie, als alleiniges Mittel angewendet, dieselben Resultate gegeben, wie die zahlreichen therapentischen Agentien in Verbindung mit europäischem Regime. M. Oppenheim.

Dencker, Christian. Ein Fall von extensiver leukämischer Infiltration der Brustdrüsen und der Haut. The Journal of the American Medical Association. 1911. Februar 11. p. 417.

Dencker berichtet über eine 47jährige Patientin, bei der seit etwa 9 Monaten die Krankheit mit Jucken und Röte der Nase begonnen hatte. Es folgte starke Schwellung der Nase, der Lippen, der Drüsen und der Ohren. Der Blutbefund ergab 110.000 weiße Blutkörperchen, $82 \%$ kleine und $6 \%$ große Lymphozyten. Die Sektion ergab die gewöhnlichen lymphatischen Hyperplasien der chrouischen lymphatischen Leuk.

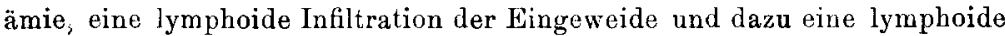
Infiltration der Haut, der Nase und der Lippen. Die Brustdrüsen waren ersetzt durch eine Masse lymphoiden Gewebes, welches in Grobem dem Sarkomgewebe ähnelte. Mikroskopisch fand sich das normale Gewebe der Mamma fast ganz geschwunden, nur ganz spärlich fanden sich in der Masse großer und kleiner Rundzellen isolierte Drüsentubuli und Gänge. Die lymphoiden Zellen infiltrieren das Bindegewebe der Warze und der Areolen, aber sie dringen nicht ins Epithel. (Die genauere Beschreibung 
der anatomischen Befunde werden veröffentlicht in den "Transactions of the Chicago Pathological Society.) Fritz Juliusberg (Posen).

Darier, J. Beitrag zum Studium der prämykotischen Eruptionen und speziell der Erythrodermie prémycosigue. Unnas Dermatolog. Studien (Unna Festschrift Bd. II). Bd. XXI. p. 490.

Darier gibt in seiner Arbeit eine vollkommene klinische Darstellung der prämykotischen Exantheme, wobei für die verschiedenen Eruptionen auch die histologischen Bilder aufs eingehendste beschrieben und erläutert werden. Speziell beschäftigt er sich mit der Erythrodermie prémycosique und kommt zu folgenden Schlüssen: 1. Unter den prämykotischen Eruptionen gibt es eine symptomatische Form, die den Namen Erythrodermie prémicosique Besnier-Hallopeau verdient. Ihre kiinischen Charaktere sind völlig scharf und ihre Effloreszenzen haben eine gleiche Struktur wie die mykotischen Tumoren. 2. Der Name Erythrodermie prémycosique muß allein diesem Krankheitstypus reserviert bleiben und darf nicbt auf alle Formen diffuser und generalisierter prämykotischer Eruptionen angewendet werden. 3. Die prämykotischen Eruptionen, seien sie umschrieben oder diffus, sind oft schwer zu diagnostizieren. Denn sie werden nicht zusammengesetzt durch die speziellen Läsionen der Mykosis, sondern gleichzeitig und manchmal allein bei gewissen Fällen, durch banale Veränderungen, die zum Teil dem Jucken und dem Kratzen zuzuschreiben sind. 4. Die Wahrscheinlichkeit der prämykotischen Natur einer Hautveränderung ist um so größer, je mehr ihre Struktur Analogien mit den mykotischen Tumoren und der Erythrodermie prémycosique ergibt.

Fritz Juliusberg (Posen).

Stancanelli, P. Eigenartiger histologischer Befund bei einer sykotischen, keloidartigen Dermatitis und Beitrag zur Bedentung und Funktion der Unnaschen Plasmazellen bei den chronisch-entzündlichen Prozessen derHaut. Giorn. internaz. d. Scienze med. Heft XXIII. 1910.

Aus den Befunden Stancanellis lassen sich folgende Schlüsse ziehen:

1. In einem Falle von sykotischer keloidartiger Dermatitis bestand die persivasale Infiltration - abgesehen von den anderen Elementen aus zahlreichen Plasmazellen, so daß die Infiltration an gewissen Stellen das Aussehen eines wahren Plasmoms annahm.

2. Dieser (vielleicht einzig dastehende) Befund macht - nach Analogie mit den anderen Plasmazellengranulomen - eine parasitäre Genese der Affektion wahrscheinlich trotz der negativen bakteriologischen Untersuchungen.

3. Die Plasmazellen Unnas entstehen hier aus den fixen Zellen des Bindegewebes und besonders aus den peritelialen Elementen, die am direktesten die Wirkung der irritierenden Ursachen erfahren und am ersten au den Prozessen der Proliferation und Neoformation von Gefäßen teilnehmen. 
4. Wie in einigen krankhaften Prozessen verfallen sie, indem sie ibre Vitalität verlieren, schnell in Nekrobiose, in anderen dagegen, wie bei der vorliegenden Läsion, zeigen sie sich ausgestattet mit einer intensiven fibroplastischen und organisierenden Aktivität.

5. Es ist anzunehmen, daß die letzte Bestimmung der Plasmazellen, wechselnd in den verschiedenen Fällen, mehr in Beziehung zu bringen ist zur Intensität, Dauer, Natur des krankhaften Agens, vielleicht auch zur Entwicklung der Affektion selbst, als zu den besonderen, ihrem Ursprung, ihrer Konstitution und funktionellen Aktivität inhärenten Eigentümlichkeiten.

J. Ullmann (Rom).

Mendes da Costa. Ein Fall von Kaposis Pigmentsarkom. Unnas Dermatolog. Studien (Unna Festschrift Bd. I). Bd. XX. p. 212.

Mendes da Costa beschreibt kurz einen Fall von Kaposis Pigmentsarkom bei einem 76jährigen Manne. Die Krankheit bestand drei Jahre. Unter fortdauernder innerer Arsenbehandlung kam es zur Heilung. Während der Behandlung kam es zu einem Erysipel, das nach des Autors Ansicht vielleicht mit die Heilung veranlaßt hat. Fine exzidierte kleine Stelle ergab einen gefäßreichen Spindelzellentumor in der Kutis, Der Autor fabt die Erkrankung als ein Endotheliom auf, das anfangs diffus über alle GefäBe ausgebreitet ist und klinisch am frühesten erkannt wird an der Extravasation in peripheren Körperstellen.

Fritz Juliusberg (Posen).

Cullen, Thomas. Chirurgische Erkrankungen des Nabels. The Journal of the Americ. Med. Assoc. 1911. Februar 11. p. 391.

Cullen behandelt in dieser Arbeit die vom Nabel ausgehenden Erkrankungen mit großer Gründlichkeit und reichlichen Literaturangaben. Die ausführlichen Krankengeschichten und eingehenden bistologischen Untersuchungen sind von gröbtem Interesse auch für den Dermatologen, aber zu kurzem Referate nicht geeignet. Fritz Juliusberg (Posen).

Schwenter-Trachsler, W. Ein Beitrag zur Akneätiologie. Unnas Dermatol. Studien (Unna-Festschrift Bd. I). Bd. XX. p. 311.

Schwenter-Trachsler impfte von 10 Aknefällen, sowohl von der Aknepustel, wie vom Komedo anf verschiedene Nährböden. Stets entwickelte sich eine weiße Kokkenkultur neben Bazillen von verschiedenen Dimensionen und dem Flaschenbazillus. Mit dem milchweißen Kokkus stellte Verfasserin weitere Versuche an. Einreibungen desselben, ebenso wie Einreibungen in die Haut des Menschen führten zu keinem Erfolge. In einem Falle aber, wo die Kultur nach dem Verfabren von Burri aus einem einzigen Kokkus hergestellt wurde, gelang es durch Einreiben auf die Stirn bei einem aknefreien gesunden Mädchen Komedonen zu erzeugen. Die Übertragung dieser Komedonen auf zuckerhaltige Nährböden gab Anlaß zum Wachsen des weißen Kokkus. Damit glaubt Verfasserin den Nachweis gebracht zu haben, daß der von ibr aus Komedonen und Aknepusteln gezüchtete weiße Kokkus der Erreger der Akne ist und nicht ein abgeschwächter Staphylococcus pyogenes altus.

Fritz Juliasberg (Posen). 
Bergengruen, Paul. Oste omyelitis des Gesichtsskelettes im Zusammenhang mit dem Epithelstrang der Gaumenraphe eines Neugeborenen. Unnas Dermatolog. Stadien (Unna Festschrift Bd. I). Bd. XX. p. 442.

Bergengruen berichtet ausführlich über einen Fall, bei dem eine tötliche septisch osteomyelitische Erkrankung mit allergrößter Wahrscheinlichkeit von der Gaumenraphe, und zwar von dem in derselben verlaufenden Epithelstrange ausgegangen ist.

Fritz Juliusberg (Posen).

Define, G. Über die Pathogenese der Elephantiasis. Giorn. internaz. d. Scienze med. H. 23. 1910.

Define beschreibt einen Fall von ausgedehnter Elephantiasis (die unteren Extremitäten, Skrotum und linker Arm waren Sitz der Erkrankung) bei einem 50jähr. Mann, der außerdem Erscheinungen einer Mitralinsuffizienz darbot. Das Studium dieses Falles führte A. zu folgenden Schlüssen :

1. Die Affektion ist auf zwei pathogenetische Faktoren zurückzuführen, nämlich a) die pathogene Wirksamkeit - und zwar in fast ausschließlicher Weise - des Staphylococcus pyogenes aureus und in geringerem Grade die des Streptokokkus ; $b$ ) die durch Mitralinsuffizienz bedingte Blutstauung.

2. Der primäre Herd der Infektion scheint im Netz der Lymphkapillaren lokalisiert; von hier ist er entweder durch Kontignität oder Metastase in die Venen oder Arterien übergegangen und hat die Entzündungen dieser Gefäße hervorgerufen.

3. Die Staphylokokken finden sich in großer Quantität und in Haufen angeordnet in den Lymphkapillaren, die davon verstopft werden, in mäßiger Zahl in den Venen und Arterien und in noch geringerer Zahl im übrigen Gewebe des Dermas und Hypodermas.

4. Die Streptokokken sind spärlich vorhanden und ihre Ketten findet man zerstreut inmitten der Staphylokokken.

5. Die Penetration dieser Kokken in die Haut ist vermutlich durch kleine Verletzungen hindurch vor sich gegangen.

6. In diesem Falle ist der Streptokokkus nicht als spezifisches Agens - im absoluten Sinne - verantwortlich zu machen.

J. Ullmann (Rom).

Königstein, H. Wien. (Abteilung Ehrmann.) Sensibilitätsstörungen bei Vitiligo. Wiener klin. Woch. 1910. Nr. 49.

Auf Grund klinischer Beobachtungen sowie experimenteller Ergebnisse führt der Autor folgende Tatsachen an: In vielen Fällen von Vitiligo und Leucoderma syphiliticum ist die Empfindung der Haut in allen Qualitäten herabgesetzt, die Reaktion derselben auf Reize vermindert. Die Vereinigung von Sensibilitätsstörungen mit Unterempfindlichkeit gegen Lintzündungsreize ist keine zufällige. Der Zusammenhang dieser pathologischen Erscheinung ist gerade durch Arbeiten der letzten Zeit verständlich geworden. Die sensiblen Nervenenden vermitteln nicht nur die Empfindung, 
sondern leiten auch streckenweise den Entzündungsreiz zu den Gefäßen. Fine Leitungsunterbrechung kann daher Störungen auf beiden Seiten hervorrufen. Viktor Bandler (Prag).

Erdmann. Über die Beziehungen zwischen der Rosacea und äußeren Augenerkrankungen. Archiv für Augenheilkunde. Bd. LXVII. H. 4.

Schon von anderen Autoren (Arlt, Fuchs) wurde eine Form der Konjunktivitis und Keratitis beschrieben, die bei der Rosacea vorkommt. Die Augenerkrankung tritt schubweise auf, wie die Rosacea und heilt oft zugleich mit dem Hautleiden aus. Erdmann stellt 21 Fälle dieser Art zusammen. Gewöhnlich handelt es sich um Frauen, die im klimakterischen Alter stehen. Die meisten waren üppig genährt und "vollblütig“. Was die Veränderungen am Auge anbetrifft, so findet man meist eine Seborrhoe der Lidränder. Auf der Conjunctiva bulbi finden sich bäufig Knötchen, die Ähnlichkeit mit einfachen Phlyktaenen zeigen. Wichtiger sind die Hornhautveränderungen: Hier bemerkt man oberflächlichere und tiefer gelegene Infiltrate, die teilweise den Charakter eines Ulcus rodens annehmen. Verf. glaubt, daß endogen wirkende Noxen, vielleicht im Verein mit äußeren Schädlichkeiten außer auf der Gesichtshaut so auch am Auge bei vorhandener Prädisposition diese beschriebenen charakteristischen Veränderungen hervorrufen können. Er schlägt für dieses Krankheitsbild den Namen Rosacea-Keratitis, bzw. Rosacea-Konjunktivitis vor. Edgar Braendle (Breslau).

Weidler, Walter Baer. Keratitis ex Acne rosacea. Medical Record. 1911. Februar 4. p. 204.

Unter Mitteilung eines Falles berichtet Weidler über Keratitis bei Acne rosacea, welche er als Keratitis rosacea bezeichnet. Sie beginnt als eine Akne der Konjunktiva, um schrittweise weiterzugehen und dann die Kornea zu befallen. Bei Keratitis rosacea kommt es zu einer sehr ausgesprochenen Schwellung der Konjunktivalgefäße bei gleichzeitiger Bildung neuer Gefäße. Dieser Vorgang ist begleitet von einer Hyperplasie der epithelialen und subepithelialen Gewebe. Der Autor konnte im Archives of Ophthalmologie, 1910, Bd. XXXIX, über 15 derartige Fälle berichten. Fritz Juliusberg (Posen). 